\title{
Design Procedure for Sizing a Submerged-Bed Scrubber for Airborne Particulate Removal
}

\author{
C. M. Ruecker
}

P. A. Scott

April 1987

Prepared for the U.S. Department of Energy under Contract DE-AC06-76RLO 1830

Pacific Northwest Laboratory Operated for the U.S. Department of Energy by Battelle Memorial Institute 


\section{DISCLAIMER}

This report was prepared as an account of work sponsored by an agency of the United States Government. Neither the United States Government nor any agency thereof, nor Battelle Memorial Institute, nor any of their employees, makes any warranty, expressed or implied, or assumes any legal liability or responsibility for the accuracy, completeness, or usefulness of any information, apparatus, product, or process disclosed, or represents that its use would not infringe privately owned rights. Reference herein to any specific commercial product, process, or service by trade name, trademark, manufacturer, or otherwise, does not necessarily constitute or imply its endorsement, recommendation, or favoring by the United States Government of any agency thereof, or Battelle Memorial Institute. The views and opinions of authors expressed herein do not necessarly state or reflect those of the United States Government or any agency thereof, or Battelle Memorial Institute.

\section{PACIFIC NORTHWEST LABORATORY operated by BATTELLE MEMORIAL INSTITUTE for the UNITED STATES DEPARTMENT OF ENERGY under Contract DE-AC06-76RLO 1830}

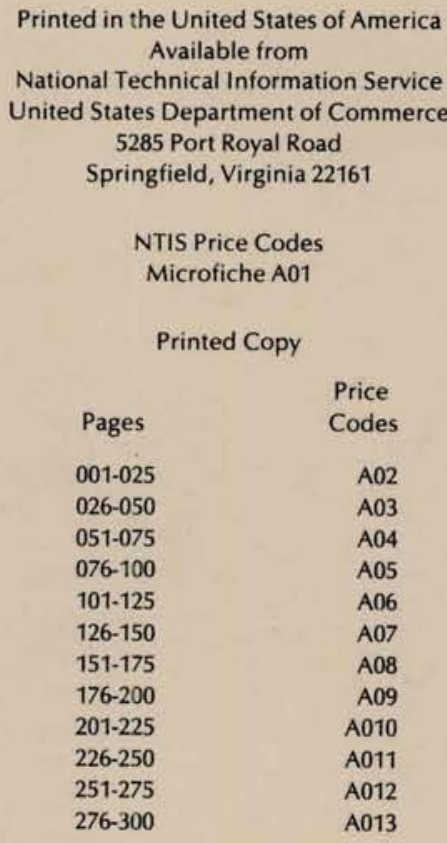


DESIGN PROCEDURE FOR SIZING A SUBMERGED-BED SCRUBBER FOR AIRBORNE PARTICULATE REMOVAL

C. M. Ruecker

P. A. Scott

April 1987

Prepared for

the U.S. Department of Energy

under Contract DE-AC06-76RLO 1830

Pacific Northwest Laboratory

Richland, Washington 99352 


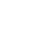


The submerged-bed scrubber (SBS) removes heat and particulate material from a gas stream by bubbling the gas through a bed of packing that is submerged in water. The SBS was originally conceived for emergency venting of nuclear reactor containment buildings; however, it is currently being considered for use in the off-gas treatment systems of liquid-fed ceramic melters (LFCMs). As high-level waste (HLW) is vitrified in an LFCM, radioactive aerosols form that must be removed from the hot off gas. In this application, the primary scrubber must quench the off gas and capture particles larger than $10 \mu \mathrm{m}$. The SBS can be designed to meet both of these criteria. It is also ideally suited for use in a remote environment necessary for HLW processing because it contains no moving parts.

Until recently, minimal information has been available for design and operation of an SBS, largely because the SBS had been considered for only a few specialized applications in the nuclear industry. The objective of this study was to develop performance correlations necessary to design and operate the SBS for various applications. Structural design procedure outlined in this report focuses on off-gas scrubbing for HLW vitrification applications; however, the method is appropriate for other applications.

The design information presented here was based on a series of experiments conducted to define the relationships that affect the aerosol collection efficiency of the SBS. These tests evaluated how derosol removal efficiency is influenced by bed diameter, packing size, aerosol solubility, inlet humidity, inlet aerosol concentration, and gas flow rate. Limited testing was also performed using a surfactant to reduce collection losses caused by re-entrainment of the scrubbing solution. A full discussion of these experiments is reported in a companion report, Parameters Influencing the Aerosol Capture Performance of the Submerged-Bed Scrubber (Ruecker and Scott 1986).

The procedure for sizing an SBS involves identifying the characteristics of the inlet gas stream, specifying the operating limits, and then selecting a 
packed bed diameter that will achieve the required gas cleaning. After the bed diameter is established, other dimensions can be specified, such as the depth of packing, cooling coil dimensions, and tank diameter.

The cleaning efficiency for the SBS is measured by the decontamination factor (DF), which is defined as the ratio of the inlet to the outlet aerosol mass flow rate. The DF for the SBS is very dependent on the superficial velocity of the noncondensible gases in the off gas, as well as the nature of the off gas as shown below. It is therefore crucial that an SBS be properly sized.

TABLE S.1. Performance Range of the SBS

$\begin{array}{llcc}\frac{\text { Parameter }}{\text { Superficial Velocity }} \text { soluble } & 0.1 \text { to } 0.35 \mathrm{~m} / \mathrm{s} & & 20 \text { to } 260 \\ \begin{array}{l}\text { (noncondensibles) } \\ \text { Superficial Velocity insoluble }\end{array} & 0.1 \text { to } 0.35 \mathrm{~m} / \mathrm{s} & 4 \text { to } 8 \\ \begin{array}{l}\text { (noncondensibles) } \\ \text { Superficial Velocity insoluble } \\ \text { (noncondensibles at } \\ \text { Various Steam-to-Air }\end{array} & 0.1 \text { to } 0.35 \mathrm{~m} / \mathrm{s} & 4 \text { to } 59 \\ \text { Ratios } & 0 \text { to } 0.5 \mathrm{~m}^{3} / \mathrm{m}^{3} & \end{array}$

These experiments were conducted in a pilot-scale SBS with a cross-sectional bed area of $0.17 \mathrm{~m}^{2}$, filled with ceramic spheres to a depth of $0.55 \mathrm{~m}$. The size range of aerosols investigated covered particles from 0.3- to 0.7-u um. This size range is typical of aerosols found in melter-generated off gas and is in the region of minimum collection efficiency for the SBS. Therefore, off gas cleaning applications involving larger particles will lead to higher DFs.

As seen in the above table, a properly sized and operated SBS has the potential to attain overall DFs of 100 , depending on the characteristics of the off gas. The SBS is ideally suited for use in the nuclear industry, and is also versatile enough to be used for more traditional off-gas cleaning applications. 


\section{ACKNOWLEDGMENTS}

Editorial assistance from Andrea McMakin was greatly appreciated. Tom Powell's assistance during the preparation of experimental apparatus and operation during testing is gratefully acknowledged. 


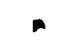

.

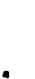

.

. 


\section{CONTENTS}

SUMMARY i i i

ACKNOWLEDGMENTS

v

1.0 INTRODUCTION AND OBJECTIVES $\ldots \ldots \ldots \ldots \ldots \ldots \ldots \ldots \ldots \ldots \ldots \ldots \ldots \ldots \ldots \ldots$

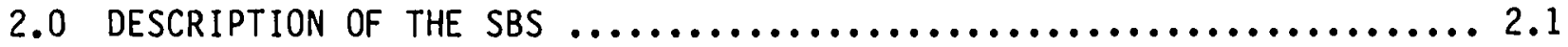

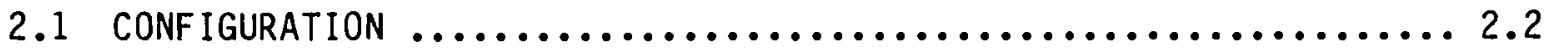

2.2 FLOW CHARACTERISTICS $\ldots \ldots \ldots \ldots \ldots \ldots \ldots \ldots \ldots \ldots \ldots \ldots \ldots \ldots \ldots \ldots \ldots$

2.3 PREDOMINANT AEROSOL CAPTURE MECHANISMS $\ldots \ldots \ldots \ldots \ldots \ldots \ldots \ldots$

3.0 Parameters Influenc ing SBS SCRUbBing PERFORMANCE $\ldots \ldots \ldots \ldots \ldots \ldots \ldots \ldots$

3.1 INLET GAS VARIABLES $\ldots \ldots \ldots \ldots \ldots \ldots \ldots \ldots \ldots \ldots \ldots \ldots \ldots \ldots \ldots \ldots \ldots$

3.2 DESIGN VARIABLES $\ldots \ldots \ldots \ldots \ldots \ldots \ldots \ldots \ldots \ldots \ldots \ldots \ldots \ldots \ldots \ldots$

3.3 OPERATING VARIABLES $\ldots \ldots \ldots \ldots \ldots \ldots \ldots \ldots \ldots \ldots \ldots \ldots \ldots \ldots \ldots \ldots$

4.0 EXPERIMENTAL RESULTS USED FOR DESIGN BASIS $\ldots \ldots \ldots \ldots \ldots \ldots \ldots \ldots \ldots \ldots$

4.1 BED CROSS-SECTIONAL AREA $\ldots \ldots \ldots \ldots \ldots \ldots \ldots \ldots \ldots \ldots \ldots \ldots \ldots \ldots$

4.2 COOLING COILS $\ldots \ldots \ldots \ldots \ldots \ldots \ldots \ldots \ldots \ldots \ldots \ldots \ldots \ldots \ldots \ldots \ldots \ldots$

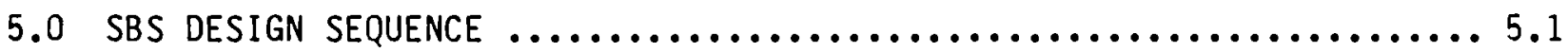

5.1 SIZING The INLET PIPE $\ldots \ldots \ldots \ldots \ldots \ldots \ldots \ldots \ldots \ldots \ldots \ldots \ldots \ldots \ldots \ldots$

5.2 DETERMINING THE INSULATION THICKNESS AROUND THE

SBS INLET PIPE ................................ 5.3

5.3 SIZING THE BED CROSS-SECTIONAL AREA $\ldots \ldots \ldots \ldots \ldots \ldots \ldots \ldots \ldots \ldots$

5.4 VERTICAL BED DIMENSIONS $\ldots \ldots \ldots \ldots \ldots \ldots \ldots \ldots \ldots \ldots \ldots \ldots \ldots \ldots \ldots . \ldots . \ldots \ldots$

5.5 SIZING THE COOLING COILS $\ldots \ldots \ldots \ldots \ldots \ldots \ldots \ldots \ldots \ldots \ldots \ldots \ldots \ldots \ldots$

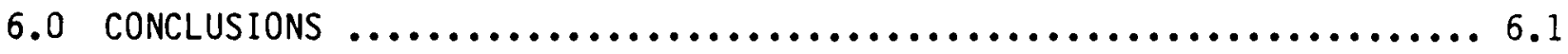

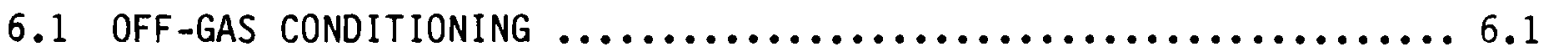

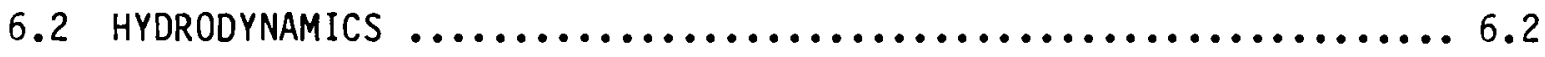




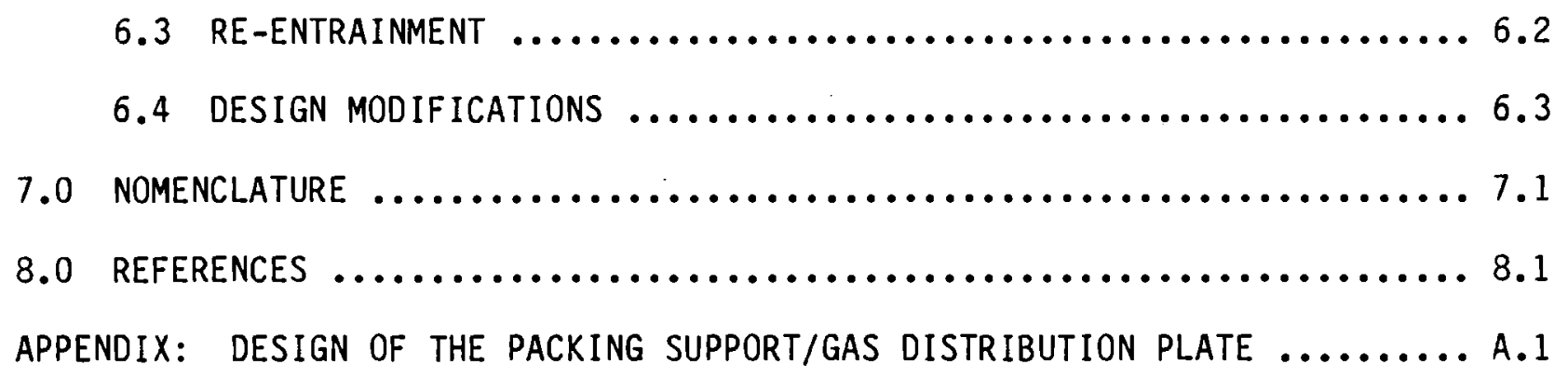




\section{FIGURES}

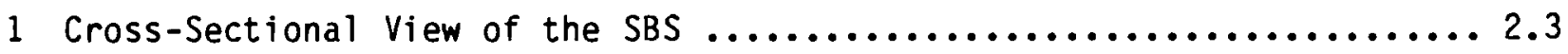

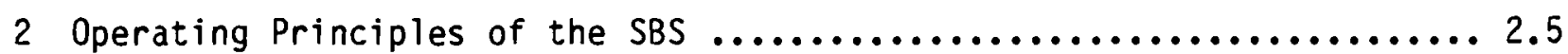

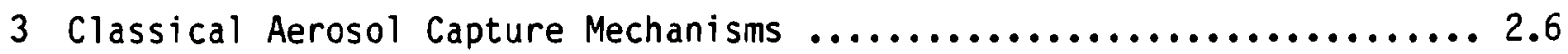

4 Design Correlations for Sizing the SBS Bed Cross-Sectional

Area Based on Insoluble Aerosols ............................... 4.2

5 Design Information for Sizing the SBS Bed Cross-Sectional

Area Based on Soluble Aerosols ...............................4.4

6 Re-Entrainment as a Function of Scrubbing Solution Concentration ..... 4.7

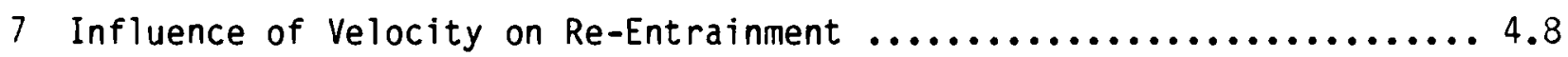

8 Film Cooler Cross-Section Details ............................ 5.2

9 Typical Axial Bed Temperature Profile ....................... 5.9

\section{$\underline{T A B L E S}$}

S.1 Performance Range of the SBS $\ldots . \ldots \ldots \ldots \ldots \ldots \ldots \ldots \ldots \ldots \ldots . . . \ldots$ iv

1 Experimentally Determined Values of the Overall Heat Transfer Coefficient, $U$.............................................4.10 
$-$

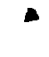
. 


\subsection{INTRODUCTION AND OBJECTIVES}

The submerged-bed scrubber (SBS) was originally developed at the Hanford Site as part of a containment vent and/or purge system to remove radioactive aerosols in the event of a core disruptive accident in a nuclear reactor (Postma 1984). The SBS is an attractive component for use in emergency vent applications because it is a passive scrubber (it requires no energy and is ready on demand) and can handle large surges of off gas. These same qualities make it a strong candidate as the primary scrubber in the off-gas system of a plant that immobilizes high-level nuclear waste (HLW) for disposal using a high-temperature solidification process. During HLW processing, radioactive aerosols are generated that must be removed before the off gas can be vented to the atmosphere. Because the off-gas system processes radioactive material, the system must be located in a containment cell. The SBS is ideal for use in a remote location because it has no moving parts. This feature minimizes maintenance and reduces the risk of equipment failure.

As part of the U.S. Department of Energy's Nuclear Waste Treatment Program, Pacific Northwest Laboratory(a) adapted the SBS to a continuousprocess off-gas system. Tests have been conducted since 1983 to determine how the performance of the SBS can be made most effective for this application (Scott, Goles and Peters 1985; Ruecker and Scott 1986). Since the SBS was initially designed for emergency vent applications, the original containment venting studies performed at the Hanford Engineering Development Laboratory (Hilliard, McCormack and Postma 1981) were not concerned with determining the optimum processing and operating conditions. This document identifies the design and operating conditions of the continuous-process SBS that maximize its scrubbing performance.

This report begins by briefly describing the configuration and operation of an SBS, including an explanation of the three primary mechanisms for aerosol capture. Section 3 discusses the parameters that influence SBS scrubbing

(a) Pacific Northwest Laboratory is operated by Battelle Memorial Institute for the U.S. Department of Energy. 
performance: process variables, design variables, and operating variables. Section 4 summarizes experimental results that were used as a design basis to size two primary components of the SBS: the cross-sectional area of the packed bed and the cooling coils. Specific design considerations are presented for key components of the SBS in Section 5 . 


\subsection{DESCRIPTION OF THE SBS}

The SBS has almost exclusively been used in conjunction with HLW processing. The reference process for stabilizing HLW for geologic disposal is to vitrify the waste using a joule-heated ceramic melter. The waste is mixed with glass-forming materials and fed into the melter as a slurry. Many of the components present in the slurry are volatile at the operating conditions of the melter, and produce an off gas that is drawn out of the melter by suction. The melter is operated under vacuum so that any leaks are directed into the off-gas system. This method of operation limits the likelihood of radioactive material leaking into the containment cell.

The off gas generated during HLW processing consists mainly of steam, nitrogen oxides, hydrogen, air-inleakage, entrained feed and aerosols of various compounds. Several of the aerosol compounds in the off gas contain radioactive material and must be removed before the off gas can be vented. The aerosols generated by the melter are typically very small ( $<1$ micron) since many of them are produced by condensation. The few large particles (>16 microns) present in the off gas are generally either entrained feed or glass fibers. The entrained feed results from the melter feed process. The feed slurry is poured into the melter through a water-cooled nozzle. Some of the feed is entrained in the off gas before reaching the glass surface. A significant portion of the large aerosols are formed as the result of bursting bubbles as the feed boils on top of the floating crust (cold cap) that covers much of the molten glass surface.

Other large aerosols are formed as streamers of molten glass are ejected into the plenum above the glass, as bubbles of escaping gases break the surface of the molten glass. The ejected glass quickly cools, forming glass "hairs" that are carried away by the off gas. The small particles are the result of condensing semivolatiles. The temperature of the molten glass in the melter is generally in the $1000-1200^{\circ} \mathrm{C}$ range. Many of the compounds in the feed are volatile at these temperatures, particularly cesium and ruthenium. As the vapors leave the melter they begin to cool, causing them to condense. 
Unfortunately, this process results in the formation of radioactive submicron particles that are very difficult to remove from the off gas.

An off-gas system for a HLW processing plant uses several different types of gas cleaning devices in series to remove radioactive material from the gas being vented to the atmosphere. The first or primary scrubber cools the off gas down to room temperature from an inlet temperature ranging from 200 to $400^{\circ} \mathrm{C}$. This scrubber removes virtually all of the large particles and some of the small aerosols from the off gas. The high-efficiency filters can then collect the remaining small particles without being prematurely plugged with large aerosols. The primary scrubber is typically required to have a minimum aerosol decontamination factor (DF) of 10 (Gurley et al. 1986). (The DF is the ratio of the inlet aerosol mass flow rate to the outlet flow rate.) Experiments by Ruecker and Scott (1986) showed that the aerosol DF for the SBS can exceed 100 under certain conditions.

\subsection{CONFIGURATION}

The SBS consists of a bed of packing, usually ceramic spheres, submerged in an aqueous pool. A cross-sectional view of the SBS as modified for continuous process off-gas systems is shown in Figure 1. The inlet pipe runs down through the center of the bed to the packing support plate. The bed-retaining walls extend below the support plate creating a lower skirt, to allow the formation of a gas bubble underneath the packing. The depth of the bubble cap is a reflection of the pressure drop across the inlet gas distribution plate and the pressure drop caused by flow through the bed. The lower skirt must extend low enough to handle the pressure drop resulting from unexpected off-gas surges. A holddown screen is used to prevent the bed from becoming fluidized at high gas velocities. A fluidized bed would result in lower scrubbing efficiencies as well as attrition of the packing. The entire bed is suspended off the floor of the SBS to allow the scrubbing solution to circulate freely through the bed.

Captured aerosols can be continuously removed from the SBS through an overflow line. This line is also used to maintain the water level at a specified height above the top of the packing. The overflow rate is determined by 


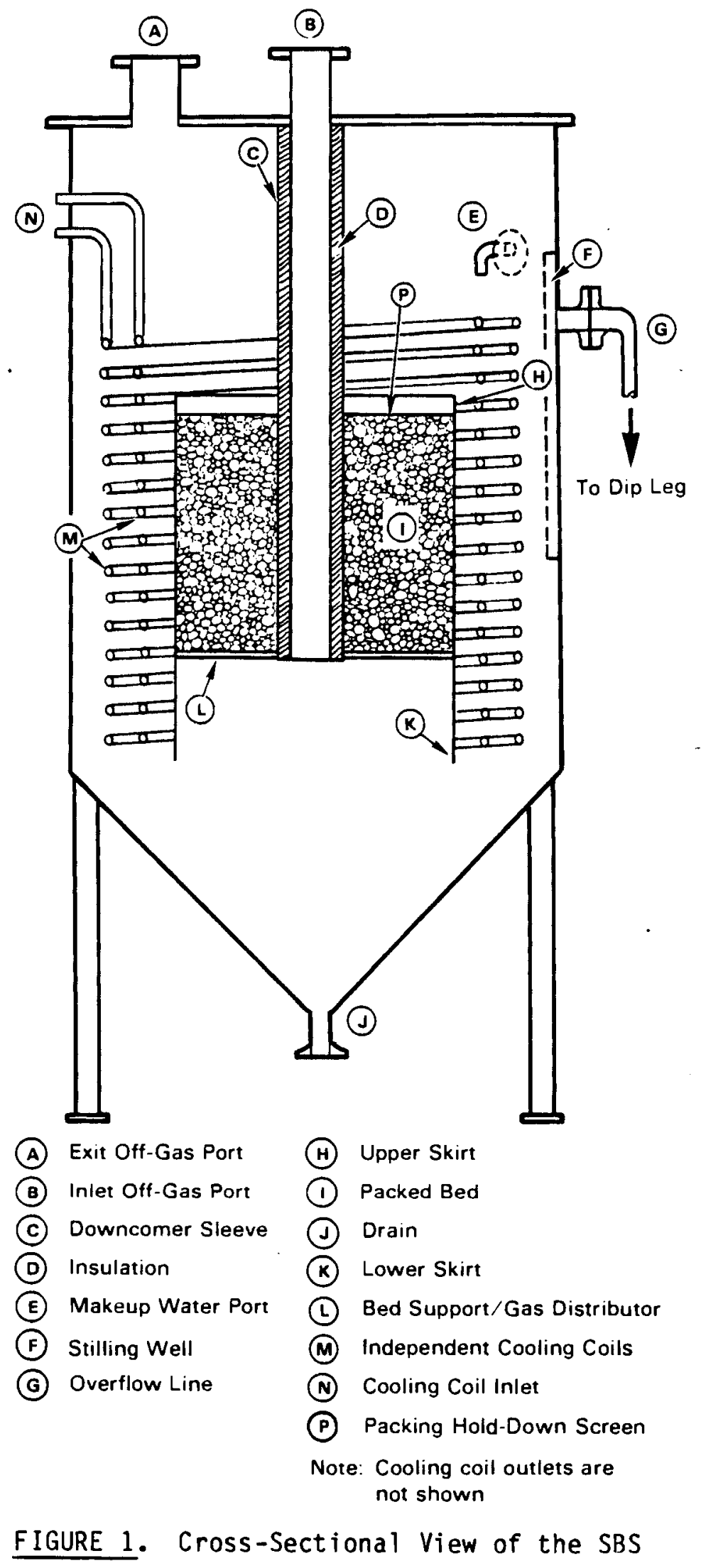


the rate of steam condensation or water evaporation and the flow rate of the makeup water. Under vacuum conditions, in order for the SBS to drain properly, the overflow line must be of an appropriate length and be equipped with either a siphon break (not shown) or a stilling well. If the pressure in the void space above the aqueous pool is $-80 \mathrm{~cm}$ of water column, for example, the overflow line must extend at least $80 \mathrm{~cm}$ lower than the liquid level with the end of the line submerged in a seal pot. The overflow rate is important in that it controls the captured aerosol concentration in the scrubbing liquor. Some settling of the larger insoluble particles may occur inside the SBS, so it could become necessary to periodically drain the SBS to remove the accumulated solids. A water sparge (not shown) can be used to resuspend the solids prior to draining as well as rinse the floor of the SBS once it has drained.

Insulation is used around the inlet pipe to prevent material from condensing on the inside walls of the pipe. Condensing vapors can cause deposits on the pipe walls that can eventually lead to plugging. To remove heat from the scrubbing solution, individual cooling coils are located in the annular region between the reservoir tank and the bed-retaining wall. The large volume of cooled scrubbing solution acts as a heat sink so that the system can handle large surges of hot off gas.

\subsection{FLOW CHARACTERISTICS}

Flow is induced through the bed by applying suction to the discharge side of the SBS. The water level inside the inlet pipe begins to fall as a vacuum is pulled on the void space above the aqueous pool. The off-gas flow begins once the pressure difference between the void space in the SBS and the inlet pipe is greater than the static head of scrubbing solution. At this point, the off gas will bubble up through the bed along the outside of the inlet gas downcomer. As the vacuum is increased, the flow rate will increase. This will result in steadily improving gas distribution as the gas bubble underneath the packing grows.

This water circulation flow pattern is shown in Figure 2. The off gas bubbling up through the bed causes the apparent density of the two-phase fluid within the bed to be less than the density of the scrubbing solution in the 


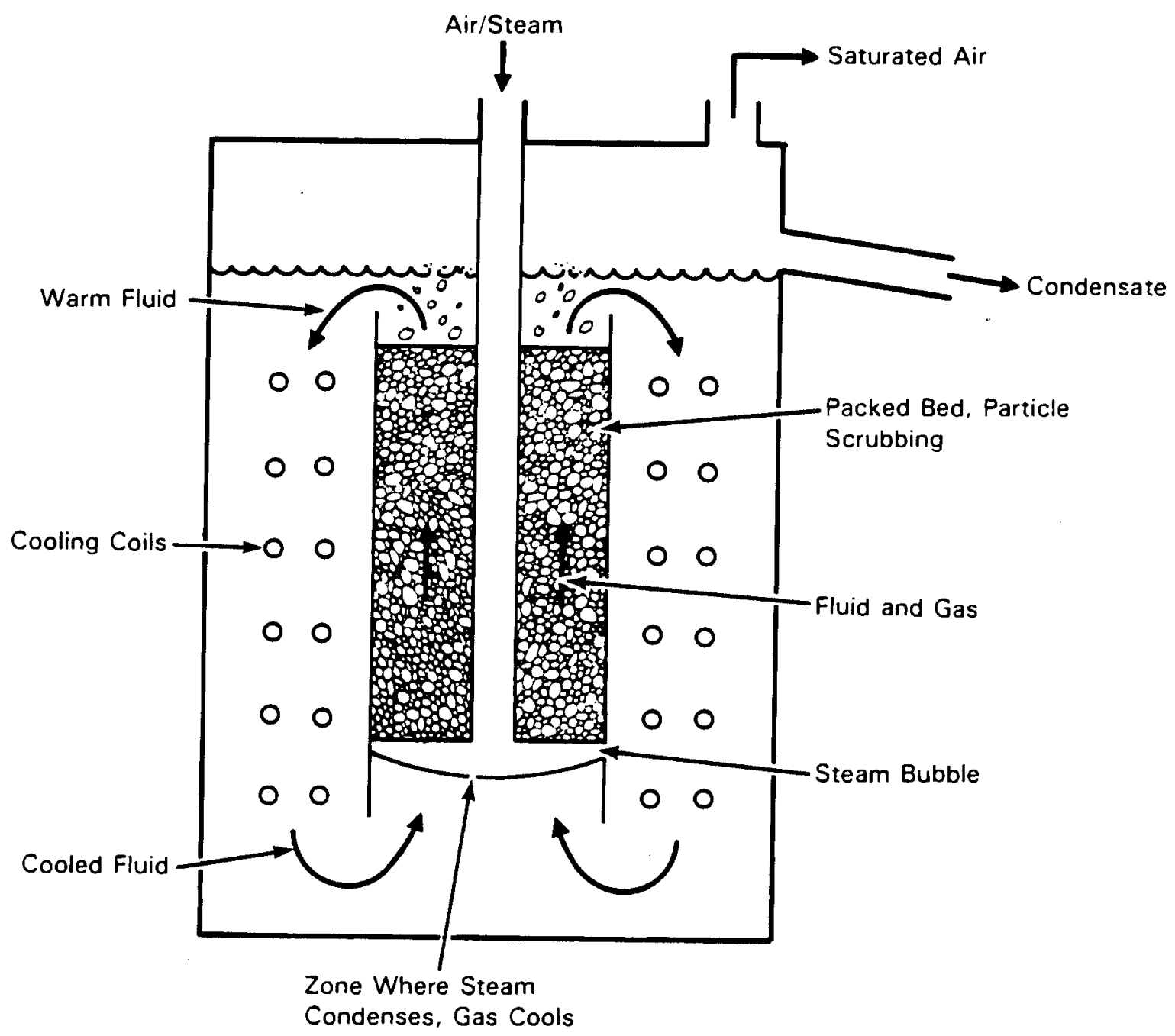

FIGURE 2. Operating Principles of the SBS

annular region of the SBS. This difference in densities results in a hydrostatic head that causes the scrubbing solution to circulate upward through the bed and downward through the annular region. The off gas helps induce flow by displacing the solution as it flows upward. The scrubbing solution is cooled in the annular region, where it flows downward over the cooling coils to remove the heat transferred from the of $f$ gas. The liquid circulation helps to prevent any buildup of captured material in the bed by constantly washing the material away. Because the scrubbing solution circulates naturally, no pump or any other mechanical device is needed. 
At low flow rates, the off gas will proceed through the bed as discrete bubbles. As the flow rate increases, the turbulence within the bubbles will increase (Garner and Hammerton 1954), causing them to grow. At still higher flow rates, the bubbles will become so large that they form continuous gas phase channels through the packing. The flow characteristics change considerably at this point. Before the flow rate reaches the point where continuous gas phase channels are formed, the actual bed velocity is determined by the terminal velocity of the bubble. Once a channel has formed through the bed, the velocity increases much more rapidly with increasing driving force. The off gas becomes less turbulent, and streamlines can be used to describe the flow pattern.

\subsection{PREDOMINANT AEROSOL CAPTURE MECHANISMS}

There are three predominant aerosol capture mechanisms that occur in the SBS: impaction, interception and Brownian diffusion. These mechanisms have been clearly defined for more common air filters such as fiber bed filters where the flow pattern around a single fiber is well understood. The classical examples of impaction, interception and Brownian diffusion are shown in Figure 3 for laminar flow around a cylindrical object.

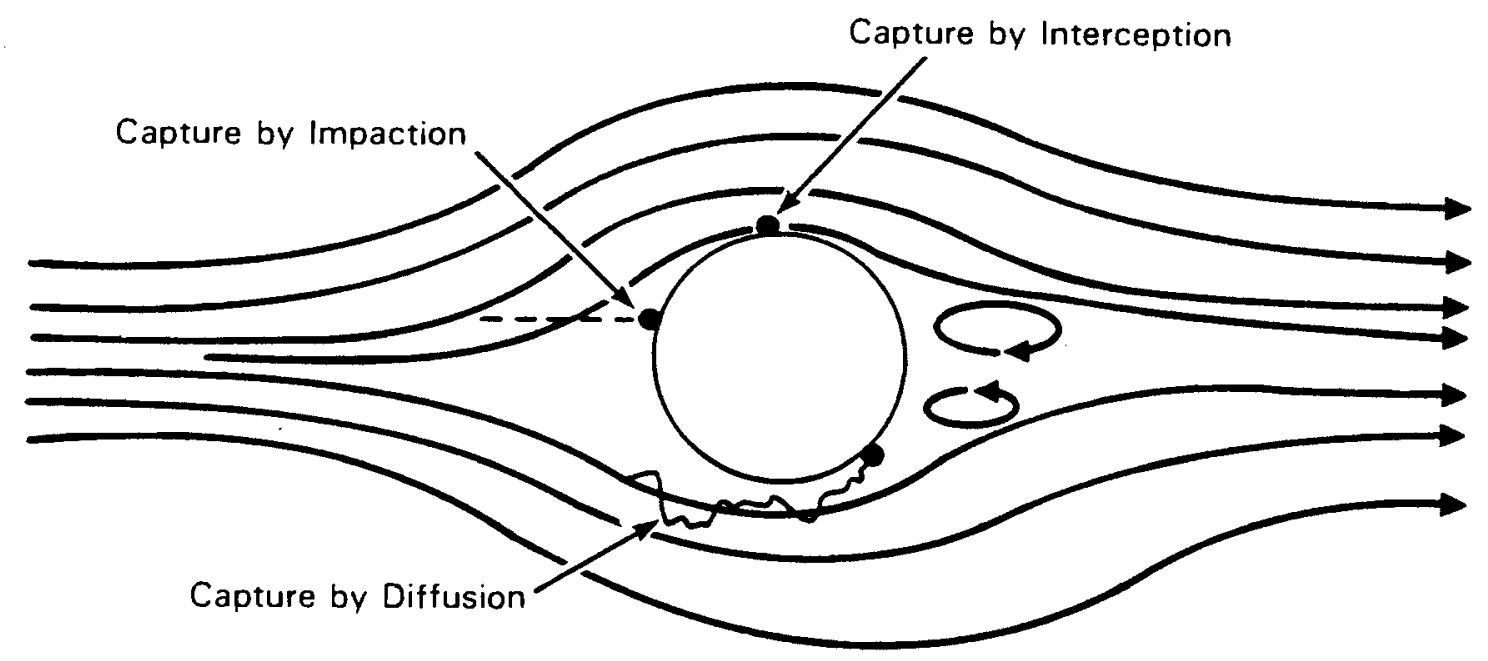

FIGURE 3. Classical Aerosol Capture Mechanisms 
The flow patterns for two-phase flow (gas and water) in the SBS are not as simple. At low flow rates, the gas phase is discontinuous, and it is inappropriate to use the traditional capture mechanisms to describe or predict what happens in the SBS. The classical descriptions of the impaction, interception and diffusion capture mechanisms are presented by Hinds (1982) and are summarized below. Also discussed is how these explanations may be modified to describe what happens in two-phase flow situations.

Impaction. An aerosol will follow a streamline as it flows along with the off gas. As the off gas approaches an obstacle, the streamlines change directions to avoid it. The inertia of large particles (usually those larger than 1 micron) causes them to leave the streamline and collide with the obstacle; thus, they are removed from the off gas. The inertial impaction process is more significant for larger particles than for smaller ones because the capture efficiency is a function of the momentum of the aerosol. Larger particles have more inertia than smaller particles at a given off-gas flow rate and therefore deviate more easily from their streamline. The impaction capture efficiency increases with off-gas velocity for all size particles because increasing the velocity increases the momentum of the particles.

In two-phase flow where the gas bubbles through the liquid, an aerosol will have contributions to its momentum from two different flow components: 1) the flow of the bubble up through the bed (an overall convection term) and 2) turbulence inside the bubble (a random motion term). Capture by inertial impaction can therefore be a result of momentum generated by one or both of the flow components. A particle can be stationary relative to the bubble but still have momentum relative to the packing as a result of the overall convection of the off gas through the bed. As the bubble tumbles through the packing, the particle may not be able to change its direction and thus will collide with the wetted packing. Aerosols can also be removed by being convectively transported to the gas-liquid interface by turbulence within the bubble. These descriptions of the impaction capture mechanism can be replaced by the classical description once the flow rate through the bed is high enough that continuous gas phase channels are formed. 
Interception. An aerosol can be removed from an air stream when the gas streamline it is following comes within one particle radius of the surface of the collecting medium. For pure interception, it is assumed that the particles follow the streamlines perfectly. This condition would apply if the particle has negligible inertia and is unaffected by Brownian motion. The collection efficiency due to interception increases as the ratio of the aerosol particle diameter to collecting surface diameter increases. Interception is essentially the only important capture mechanism for aerosols in the particle size range of minimum collection efficiency. The particle size corresponding to the lowest collection efficiency is usually between 0.1 and 1.0 microns for most aerosol filtering devices (Hinds 1982; Shaw 1978; McCarthy et al. 1976; Calvert 1977). This region is commonly referred to as the hard-to-capture size range. Particles in this range are too small to have enough momentum to be removed by impaction, yet too large to be influenced by Brownian motion (described in the next section), thus leaving interception as the only effective means of capture. Particles outside of this range will be captured more efficiently due to impaction for large particles and Brownian diffusion for small particles.

Interception is commonly claimed to be the only capture mechanism that does not depend on the flow rate of the gas. This statement is true as long as the flow pattern around the obstacle does not change, because the probability of being captured by interception, for an aerosol of a given size, is determined by how many streamlines pass within one particle radius of the collecting medium. In actuality, significant changes in the gas flow rate can change the flow pattern, thus making the interception mechanism somewhat dependent on the flow rate.

The classical description of interception is easily applied to the SBS when the gas flow rates are high enough to form continuous gas-phase channels through the packing, but it is not quite as clear how this mechanism applies when the gas flows as bubbles. The description of interception as applied to the SBS must include particles removed when turbulence inside the bubble brings the aerosols within one particle radius of the scrubbing solution. The flow 
patterns within the bubble change rapidly with velocity and are no longer constant. Thus, it is no longer accurate to assume that the interception capture mechanism is independent of the gas flow rate.

Brownian Motion (Diffusion). Brownian motion is largely responsible for the removal of particles less than 0.1 micron in size. The path of a small particle is affected by collisions with surrounding gas molecules. Submicron particles are light enough that the momentum of the gas molecules is sufficient to slightly change the direction of the aerosol. At any given moment, the aerosol will be hit by more molecules on one side than another, causing it to slightly deviate from its original path. The random bombardment of the gas molecules causes the submicron aerosol to follow an erratic path. This phenomenon is known as Brownian motion or diffusion. This motion increases the probability of a particle hitting the surface of a collecting medium while traveling past on a nonintercepting streamline. Capture by Brownian motion is enhanced by lower gas velocities, since more time is allowed for a particle to diffuse to the surface of the collecting medium.

The classical mechanism of capture via Brownian motion is easily applied to the two-phase flow situation, because this mechanism does not strongly rely on the streamline concept. Brownian motion is assumed to be responsible for any aerosol that is captured as a result of the aerosol diffusing to the gasliquid interface. 


\author{
.
}

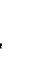

列 


\subsection{PARAMETERS INFLUENCING SBS SCRUBBING PERFORMANCE}

The aerosol scrubbing performance of the SBS is controlled by many parameters, which can be divided into three broad categories. The first category comprises the process variables or inlet conditions. These variables are generally determined by the process in which the aerosols are generated, although they can sometimes be changed, if justified by the resulting increase in the aerosol removal efficiency. The second category includes the dimensions and configuration of the SBS that are determined during the design stage. The last category consists of the actual operating parameters for the SBS.

\subsection{INLET GAS VARIABLES}

Inlet conditions are usually given in the design specifications. The conditions important to SBS performance include the off-gas flow rate, steamto-air ratio, humidity, inlet temperature, aerosol solubility, inlet aerosol concentration and aerosol size distribution. In some instances it may be desirable to modify the inlet conditions to enhance the performance of the SBS. The influence of each of these process variables is described below.

Superficial Velocity. The superficial velocity is defined as the volumetric flow rate, at standard conditions, of the noncondensible gases in the of $f$ gas, divided by the cross-sectional area of the empty bed. The superficial velocity is included as a process variable, because it only depends on the volumetric flow rate for a given SBS design. As might be expected, the superficial velocity has a significant influence on the scrubbing efficiency of the SBS. Ruecker and Scott (1986) showed that the scrubbing efficiency decreased with increasing flow rate for insoluble aerosols in the "hard-to-capture" size range ( 0.3 to 0.7 microns). However, similar experiments with soluble aerosols of the same size range did not show a trend in performance with velocity. The efficiencies achieved during these soluble-aerosol experiments was limited by re-entrainment of the scrubbing solution by the exiting gas. This re-entrainment masked the influence of superficial velocity on performance. 
One important variable in terms of aerosol removal performance appears to be the residence time of the aerosol within the bubble. Because an aerosol within a bubble must be transported by some mechanism to the gas-liquid interface, it follows that the longer the aerosol is in the bubble, the more likely it will traverse the necessary distance to come in contact with the scrubbing solution. This explanation by itself does not necessarily imply that aerosol removal is always more efficient at lower flow rates; higher flow rates can lead to greater turbulence within the bubble (Garner and Hammerton 1954), thus resulting in increased capture by impaction and interception. The turbulence present in the bubble as it rises through the bed may also lead to particle agglomeration, making the particles easier to capture by impaction (Levich 1962). This increased particle movement within the bubble may more than compensate for the shorter residence time of the particle in the bed.

It is difficult to isolate the effects of flow rate on scrubbing efficiency. Higher flow rates lead to an increase in re-entrainment; thus it becomes difficult to identify how the initial capture rate really changes with increasing velocity. In addition, as the flow rate increases, more and more of the gas will flow through channels in the bed, as opposed to forming discrete bubbles. This gradual change in the flow pattern is another factor that contributes to the difficulty of separating the actual influence of flow rate on scrubbing efficiency within a bubble.

Because re-entrainment increases with velocity, it is probably true that the overall scrubbing performance also decreases with velocity, even for large particles. The effect reduces the improvement in collection predicted by the classical capture mechanisms. When designing an SBS, it is important that the effect of the superficial velocity on the flow pattern within the bed be understood in order to predict how the aerosol capture performance will be influenced by the superficial velocity for the size distribution of interest.

Steam-to-Air Ratio. The presence of steam in the off gas will enhance the capture performance of the SBS in several ways. As the off gas comes in contact with the scrubbing solution, the off gas begins to cool, causing the steam in the off gas to condense. Although most of the steam condenses on the scrubbing solution liquid interface, some steam condenses on the aerosols present in 
the off gas. The condensate makes the aerosols effectively larger, and thus easier to capture. The condensing steam also causes an aerodynamic draft toward the condensing surface, known as Stephan flow (Hinds 1982). This draft pulls aerosols toward the gas-liquid interface or toward the growing droplets. In either event, the draft improves scrubbing performance. Thermophoretic and diffusiophoretic forces will also result that influence the transport of the aerosols, directing them toward either the growing droplets or collecting surfaces. The process of condensing steam to enhance aerosol capture through Stephan flow, thermophoresis, and diffusiophoresis is known as flux-force/ condensation (Calvert and Gandhi 1977). Examples of using flux-force/ condensation to enhance aerosol capture are given by Jacko and Holcomb 1978; Rich and Pantazelos 1974; Calvert and Jhaveri 1974; and Calvert et al. 1977.

If little steam is present in the off gas, it may be desirable to inject more steam into the inlet line to increase the scrubbing efficiency of the SBS. Although it has not been demonstrated, it is conceivable that significant improvements in the scrubbing efficiency may be obtained if very high ratios of steam to air (>4) are used. If the steam-to-air ratio is high enough, the bubbles produced at the inlet plate may undergo a significant reduction in size as the steam within the bubble condenses. This size reduction would decrease the transport distances to the gas-liquid interface. It would also increase the effective size of the aerosols as the steam condensed on them, resulting in an aerodynamic draft toward the condensing surface, and increasing the aerosol concentration within the bubble. All of these changes would assist in aerosol removal.

Humidity. The inlet humidity and temperature profile are important because they determine the extent and location of steam condensation. As previously mentioned, if the steam does not condense until it exits the inlet pipe and comes in contact with the water, most of the condensation will occur at the gas-liquid interface and not on the aerosols. If the off gas is cooled from within, before exiting the inlet pipe, the steam will condense on the aerosols, resulting in particle growth. The aerosols will also become pre-wetted, which is important for insoluble aerosols, as will be discussed later. 
The off gas must be cooled from within itself to cause the steam to condense on the aerosols. If a heat exchanger is used to cool the off gas, the steam will condense predominantly on the heat-transfer surfaces. On the other hand, if a sufficiently cold gas is injected into the gas stream, the off gas will suddenly fall below its dew-point temperature. The steam will then preferentially condense on the aerosols instead of the walls of the inlet pipe or by undergoing homogeneous nucleation (Hidy 1984). Experiments conducted by Ruecker and Scott (1986) showed that the DF increased approximately four-fold for insoluble aerosols when the inlet conditions to the SBS were below the dew point of the off gas. These results demonstrate the importance of controlling the point at which the steam condenses.

Inlet Temperature. The inlet temperature should have little effect on SBS performance, other than determining whether the off gas is entering the SBS above or below its dew point, until the inlet temperature is high enough to establish a significant radial temperature profile within the bubble. Developing a radial temperature gradient, with the gas at the center of the bubble being hot and that at the gas-liquid interface being cold, would increase particle migration toward the interface. An aerosol in a steep temperature gradient will tend to move down the gradient (in this case, toward the collecting media) because the gas molecules striking the particle from the hot side will have more momentum. This aerosol transport mechanism is known as thermophoresis (Schifftner and Hesketh 1986).

A high inlet temperature has other advantages. The higher temperature will allow higher steam-to-air ratios to be used without exceeding the saturation limit of the off gas. As the scrubbing solution quenches the off gas, not only will the steam condense, but the specific volume of the noncondensible gases will decrease as the temperature drops. The combined effect may result in a significant reduction in the size of the bubble, increasing the probability of the aerosol being captured.

Aerosol Solubility. The solubility of the aerosol in the scrubbing solution is one of the most important parameters that influences the aerosol capture performance of the SBS. Ruecker and Scott (1986) have shown that the decontamination factor (DF), defined as aerosol mass flow rate divided by the 
mass flow rate out, for sodium chloride aerosols in the range 0.3 to 0.7 microns is typically around 100 while the corresponding DF for titanium dioxide is approximately 10 . This order-of-magnitude difference in scrubbing performance is explained by the solubility properties of the two aerosols. An aerosol must be able to pass through the gas-liquid interface within the bubble to be captured by the scrubbing solution. Soluble aerosols can easily do this. As soon as a soluble aerosol migrates to the interface, its solubility causes it to be pulled into the scrubbing solution. Insoluble aerosols, on the other hand, cannot easily penetrate the interface because of the surface tension of the liquid and the wettability of the particle (Goldschmid and Calvert 1963).

Insoluble aerosols must have sufficient momentum to overcome the surface energy of the interface, or they will either bounce off the interface or inelastically collide with the surface. In the latter case, the particle will sit on the surface of the scrubbing solution until the motion of the bubble or the particle's own weight cause it to become wetted, so that it can be absorbed by the liquid. If the particle has not been absorbed by the scrubbing solution by the time the off-gas bubble reaches the surface of the aqueous pool, it can become re-entrained in the exit off gas.

The particle on the boundary is not moving relative to the liquid side of the interface, but it is moving relative to the packing and therefore has a certain amount of momentum. When the bubble reaches the surface, the scrubbing solution abruptly stops while the off gas continues. The attraction of the partially-captured aerosol to the scrubbing solution must be strong enough to overcome the momentum of the particle. Otherwise, the particle will be separated from the liquid by the shearing action of the off gas as it leaves the scrubbing solution.

Steam can be useful in overcoming the resistance to collection associated with penetrating the interface. If steam condenses on an aerosol, the aerosol becomes pre-wetted and can thus easily penetrate the interface. Another way of decreasing the resistance of the gas-liquid interface is to use a surfactant to lower the surface tension of the scrubbing solution. The surfactant must be introduced into the inlet gas so that it is sufficiently concentrated at the bubble surface. 
Inlet Aerosol Concentration. Ruecker and Scott (1986) found that the DF for soluble sodium chloride aerosols increased with increasing concentration. In fact, the outlet concentration remained constant while the inlet concentration was varied from 500 to 2700 particles $/ \mathrm{cm}^{3}$. This result suggests that the scrubbing efficiency is limited by re-entrainment, i.e., controlled by the amount of material being re-entrained as opposed to the amount penetrating the SBS. It follows that the SBS should remain efficient at high inlet concentrations of soluble aerosols. This result was in fact observed by Hilliard, McCormack and Postma (1981) in tests involving sodium fire aerosols. In these tests, the sodium mass loading was around $10 \mathrm{~g} / \mathrm{m}^{3}$ while the total aerosol mass loading in the experiments conducted by Ruecker and Scott was in the range of 0.1 to $0.5 \mathrm{mg} / \mathrm{m}^{3}$. Hilliard, McCormack and Postma still reported DF.s in the 100 range despite the presence of significant re-entrainment as suggested by their data. The sodium fire derosols investigated $\left(\mathrm{Na}_{2} \mathrm{O}_{2}, \mathrm{Na}_{2} \mathrm{O}, \mathrm{Na}_{2} \mathrm{CO}_{3}\right.$ and $\mathrm{NaOH}$ ), are all water soluble, so the scrubbing performance is assumed to be re-entrainment limited. The fact that the scrubbing performance dropped significantly as the concentration of sodium built up in the scrubbing solution indicates that the performance was indeed being controlled by the amount of material being re-entrained.

Insoluble aerosols, in contrast, have a different effect on scrubbing performance. Ruecker and Scott (1986) in their analysis of titanium dioxide, suggest that the scrubbing performance for insoluble derosols is not limited by re-entrainment, and that efficiency increases with inlet concentration. This result implies that the percentage of particles actually penetrating the SBS decreases with increasing concentration. The higher inlet concentration results in more interactions between particles. The agglomeration of aerosols occurs as a consequence of the collisions, resulting in a larger particle size distribution. This process is known as Brownian coagulation (Calvert and Englund 1984). Large insoluble agglomerates that migrate to the gas-liquid interface can thus more easily penetrate the interface. This results from the particles either having more momentum on impact or being too heavy for the interface to support. 
Aerosol Size Distribution. The scoping studies performed with the SBS by Ruecker and Scott (1986) used soluble and insoluble aerosols in the size range of 0.3 to 0.7 microns. This size range was determined experimentally to be the size range of minimum collection efficiency, i.e., aerosols outside of this range are removed more efficiently.

Descriptions of the classical aerosol capture mechanisms imply that, for small particles, the scrubbing efficiency increases with decreasing velocity, and for large particles, the efficiency increases with increasing velocity (Hinds 1982). For the SBS, this statement is probably true for small particles, but not for large particles. Recause of several competing effects, it is difficult to predict how the collection efficiency of large particles will change with flow rate. As the velocity increases, more and more large particles are removed by the increase in inertial forces. Some particles may be captured before they enter the packing. The premature capture occurs because the particles cannot complete the U-turn at the exit of the downcomer, and thus impact on the gas-liquid interface below the gas bubble. Higher gas flow rates also lead to increased turbulence inside the bubbles, which increases particle mobility and favorably influences the capture performance. On the other hand, high flow rates lead to shorter residence times as well as to the formation of continuous-gas phase channels through the bed, both of which tend to lower scrubbing performance. Another factor that adversely influences the scrubbing efficiency is re-entrainment, which becomes more significant at higher flow rates. It is difficult to predict whether the increased velocity and turbulence caused by higher flow rates will offset the decrease in performance caused by channeling and shorter residence times.

In summary, as the gas velocity is increased, the mechanisms that adversely influence the capture of large particles are probably more pronounced than those that enhance efficiency. That is, the composite scrubbing efficiency for large particles probably decreases with increasing velocity, which is opposite to the predictions based on classical capture mechanisms.

Particles larger than 1 micron were not investigated because suitable means for generating such particles were not immediately available. The experiments conducted by Hilliard, McCormack and Postma (1981) used sodium 
aerosols ranging in size from 3 to 6 microns aerodynamic mass median diameter. It is difficult to directly compare their work to the work of Ruecker and Scott (1986) for two reasons. The inlet concentration used by Hilliard et al. was several orders of magnitude higher than that used by Ruecker and Scott, and there were significant amounts of captured aerosols in the scrubbing solution in the 1981 experiments. The fact that the Hilliard et al. DFs remained in the 100 range suggests that the SBS can efficiently remove large aerosols. However, in those experiments, the increase in re-entrainment with time makes it difficult to determine whether scrubbing performance increases or decreases with velocity for these larger particles.

\subsection{DESIGN VARIABLES}

Design variables are those that the engineer controls at the design stage of the SBS: the size of the inlet pipe, the bed diameter, packing shape and size, depth of packing, scrubbing solution level and disengagement height. Only the bed diameter, packing size, and depth of packing will be discussed here because the other parameters do not significantly influence scrubbing performance.

Bed Diameter. The bed diameter is important in establishing the flow pattern and velocity through the bed. The larger the bed diameter, the more difficult it is to evenly distribute the incoming off gas. It is desirable to evenly distribute the gas so that the lowest bed velocities can be obtained. Good gas distribution also results in a higher liquid-to-gas ratio for each bubble, which improves of $f$-gas quenching.

The only advantage of increasing the bed diameter beyond a certain point is that the liquid-to-gas ratio continues to increase. The lowest possible bed velocity within the bed is controlled by the terminal velocity of the bubble. As the flow decreases, the frequency of bubble formation decreases (Benzing and Myers 1955). In conclusion, the bed diameter should be designed as large as possible under two constraints: the cost of larger equipment and the effectiveness of the distribution plate to distribute the gas. Information pertaining to the design of a sieve plate for gas distribution is given in Appendix A. 
Packing Size. Ruecker and Scott (1986) investigated both $0.3-\mathrm{cm}$ and $1-\mathrm{cm}-$ diameter ceramic packing. The tests showed that the $1-\mathrm{cm}$ packing consistently out-performed the smaller packing. This result is opposite of what would be expected. The particle collection efficiency would be expected to increase with decreasing packing size for particles larger than $0.3 \mu \mathrm{m}$ (Calvert and Englund 1984). Both packings had the same void fraction, so the difference in performance at a given superficial velocity is not a result of different interstitial velocities. A plexiglass model of the SBS was constructed in order to observe the actual flow patterns in the two beds. The void spaces in the $1-\mathrm{cm}$ packing were large enough to allow the formation of discrete bubbles. The 0.3-cm packing, on the other hand, did not have enough space between spheres for bubbles to form. Instead, continuous gas channels were formed through the packing, which resulted in lower residence times, lower surface-to-volume ratios and the corresponding decrease in performance.

Depth of Packing. The influence of packing height on performance was not investigated during the characterization study of the SBS conducted by Ruecker and Scott (1986). A bed height of $0.55 \mathrm{~m}$ was used for all of their experiments. The influence of the depth of packing on aerosol removal efficiency was not performed because the study was geared toward applications in the HLW reprocessing industry. In this case, the water level is controlled by the depth of water necessary to quench the off gas rather than the depth of packing necessary to achieve the desired aerosol removal efficiency. Packing heights above $0.55 \mathrm{~m}$ would lead to excessive pressure drops across the SBS, thus possibly requiring more than one blower to process the off gas through the entire filtering system. The scrubbing performance should always increase with the depth of packing until the point is reached where the performance is limited by re-entrainment.

\subsection{OPERATING VAR IABLES}

Because it is a passive system, very few operating variables are associated with the SBS. The only operating variables that significantly influence the scrubbing performance involve the scrubbing solution. The operator can 
control the concentration of captured aerosols in the scrubbing solution, the scrubbing-solution temperature and the addition of any additives.

Scrubbing-Solution Concentration. Before operation, the SBS is filled with process water that is free of captured aerosols. As the system begins processing the off gas, the scrubbing solution within the SBS will begin to accumulate captured material. The scrubbing-solution concentration will continue to increase until the concentration of soluble captured aerosols and suspended insoluble aerosols reach steady-state values. At this point, the amount of material being removed by the SBS is equal to the amount of insoluble material settling in the bottom of the SBS plus the material leaving the SBS with the scrubbed off gas or through the overflow line.

The scrubbing-solution concentration can therefore be controlled by adjusting the overflow rate. If the scrubbing-solution concentration is too high, makeup water can be injected into the SBS to increase the overflow rate, lowering the solution concentration. Losses due to re-entrainment of scrubbing solution increase with solution concentration, so it is desirable to keep the captured aerosol concentration as low as possible.

Scrubbing-Solution Temperature. The temperature of the scrubbing-solution in part determines the exit temperature of the off gas which, in turn, determines how much water will leave the SBS as humid air. Lowering the temperature of the scrubbing-solution either increases the water overflow rate or reduces the amount of makeup water necessary to achieve the desired overflow rate. The solution temperature also determines the cooling duties of the coils in the annular region of the SBS. The actual influence of scrubbing solution temperature on performance has not been tested, but preliminary indications are that increases in temperature lead to decreases in scrubbing performance. This trend is probably more related to how the temperature of the scrubbing solution affects re-entrainment than how it influences the initial aerosol capture.

Additives. An experiment was conducted by Ruecker and Scott (1986) in which re-entrainment was determined as a function of sodium chloride concentration in the scrubbing solution. As expected, the outlet aerosol concentration increased as sodium chloride was added to the scrubbing water. At the end of 
the experiment, a small amount of Dow defoamer DB-110A® was added to the scrubbing solution. After the defoamer was added, the outlet particle concentration dropped below the concentration measured before any sodium chloride.was added to the scrubbing solution. This experiment has been applied only to sodium chloride in the scrubbing solution and has not been tested under actual operation. However, it does clearly present the possibility of using an additive to control re-entrainment.

Dow Corning Corporation, Midland, MI. 
$+$

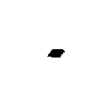


the experiment, a small amount of Dow defoamer DB-110A ${ }^{\circledR}$ was added to the scrubbing solution. After the defoamer was added, the outlet particle concentration dropped below the concentration measured before any sodium chloride was added to the scrubbing solution. This experiment has been applied only to sodium chloride in the scrubbing solution and has not been tested under actual operation. However, it does clearly present the possibility of using an additive to control re-entrainment.

Dow Corning Corporation, Midland, MI. 
.

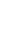
列 


\subsection{EXPER IMENTAL RESULTS USED FOR DESIGN BASIS}

Experimental results are used to size two components of the SBS: the bed cross-sectional area and the cooling coils located in the annular region of the SBS. A description of the experimental procedure and apparatus used to generate the following results was presented by Ruecker and Scott (1986).

\subsection{BED CROSS-SECTIONAL AREA}

The scrubbing performance of the SBS is mainly determined by the superficial velocity of the off gas and by the captured aerosol concentration in the scrubbing solution for a given off-gas condition. The initial capture performance is strongly influenced by the superficial velocity and the steam-to-air ratio, while particle re-entrainment is controlled by the superficial velocity and the captured aerosol concentration in the scrubbing-solution. To properly size the bed, information is needed on both the initial capture performance and the degree of re-entrainment expected over a large range of operating conditions.

Influence of Superficial Velocity on Scrubbing Performance. The superficial velocity has a significant influence on the scrubbing efficiency of the SBS, as seen in Figure 4. The results shown in this figure were based on titanium dioxide aerosols in the size range of 0.3 to 0.7 microns. For this size range, the scrubbing efficiency decreases with increasing flow rate. This result is expected, because the scrubbing efficiency should drop as the residence time decreases.

The actual initial aerosol capture performance does not fall off as quickly as suggested by Figure 4. Even though the SBS had no significant amounts of captured aerosols in the scrubbing solution, material was present in the scrubbing solution that could be re-entrained. Because the particle size analyzer was an optical unit, it could not be determined whether the material coming out of the SBS was from the aerosol generator or from residual material present in the process water used to fill the SBS. The re-entrainment of foreign material increased with flow rate, tending to lower the right-hand side 


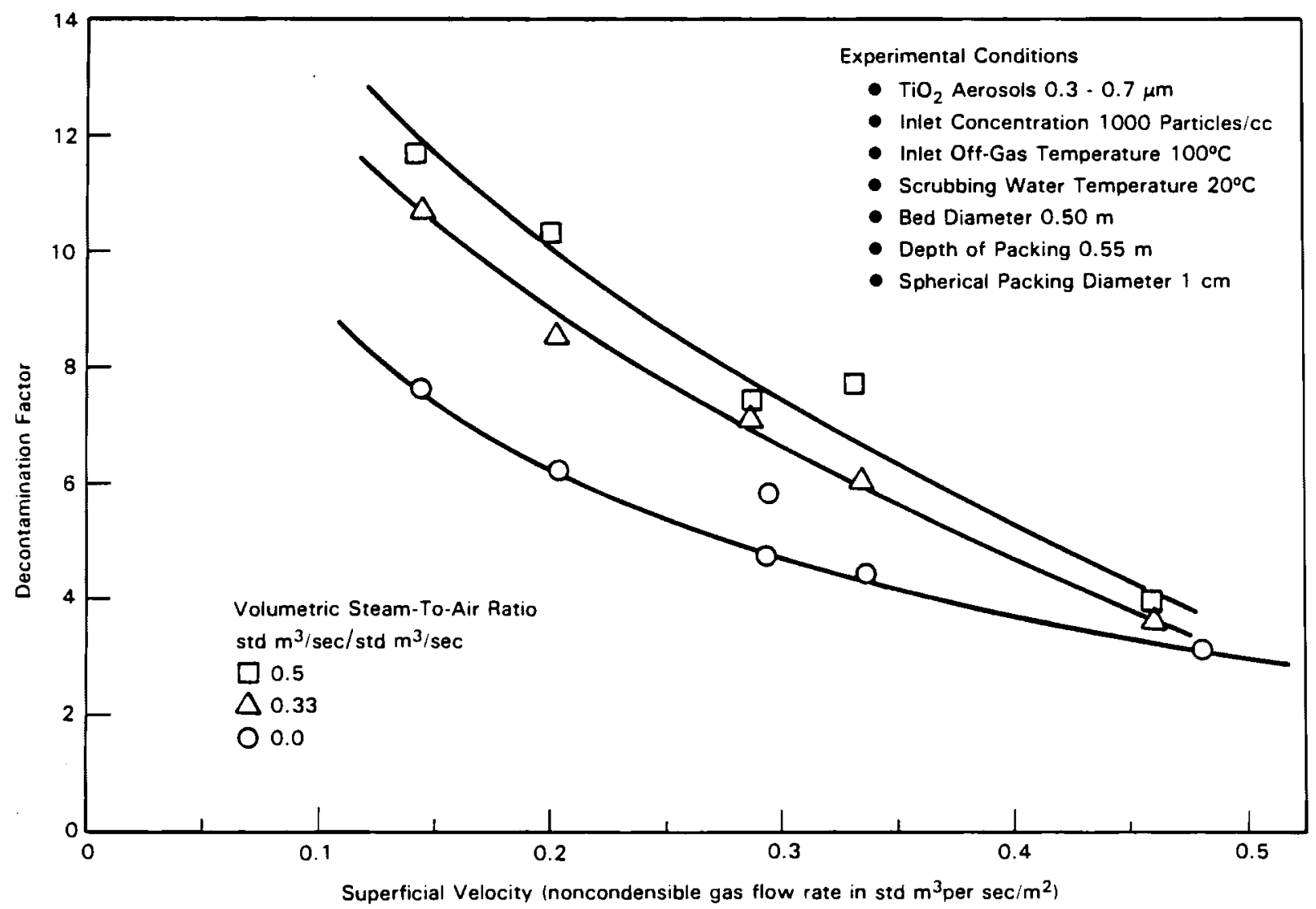

FIGURE 4. Design Correlations for Sizing the SBS Bed Cross-Sectional Area Based on Insoluble Aerosols

of the curves shown in Figure 4. In fact, at high flow rates, the re-entrainment was sufficient to almost completely mask any benefit that steam may have had on performance.

Not only does scrubbing efficiency increase with decreasing velocity, but the influence of steam also becomes more pronounced. The expected result is that steam has more of an influence at high velocities, because the condensation of the steam leads to larger particles that are more easily removed by impaction. The decrease in importance of steam with increasing velocity is probably the result of two different phenomena: 1) the influence of steam at high velocities is overshadowed by re-entrainment, and 2) at lower velocities, the aerosols have more time to diffuse, thus leading to higher collection efficiencies. 
Instead of condensing on the aerosols, most of the steam condenses at the gas-liquid interface, producing a draft toward the interface known as Stephan flow (Hesketh 1986). This phenomenon enhances the transport of aerosols to the collecting surface. The increase in the particle movement will be more noticeable at longer residence times. The combination of re-entrainment and Stephan flow tends to decrease the contributions of steam at high gas velocities and enhance the collection efficiency due to steam at low gas velocities.

The off gas for an actual application of the SBS will not be the same as the concentrations and size ranges used in the experiments conducted by Ruecker and Scott (1986) (inlet concentrations of 1000 particles/ $\mathrm{cm}^{3}$ in the range of 0.3 to 0.7 microns). Similar plots for different sizes of aerosols at different inlet concentrations would be useful for design purposes. Unfortunately, the generation of such plots is not feasible because of the number of experiments necessary and the associated costs. Instead the results presented by Ruecker and Scott (1986; summarized in Section 3) can be used to estimate how the curves shown in Figure 4 would change as a function of various parameters. The experimental conditions for Figure 4 were chosen as representing a worstcase situation because the aerosols are in the size range that is most difficult to capture. Therefore, if used for design purposes, they may lead to conservative bed dimensions.

As mentioned in Section 3, a similar set of experiments was conducted with a soluble aerosol (Figure 5), but so much scatter exists in the data that no trends could be observed. Though the extreme degree of scattering makes the data difficult to use for design correlations, it does show that the soluble aerosols are much easier to capture than the insoluble aerosols.

The data presented in Figure 4 suggest that the residence time is indeed one of the primary controlling factors. It is therefore desirable to increase the size of the bed to reduce the superficial velocity, which will also help limit re-entrainment. As the bed diameter is decreased, the liquid-to-air ratio inside the bed decreases as the off gas occupies a larger portion of the bed volume. The shorter residence time and smaller liquid volume makes quenching of hot off gas less effective. 


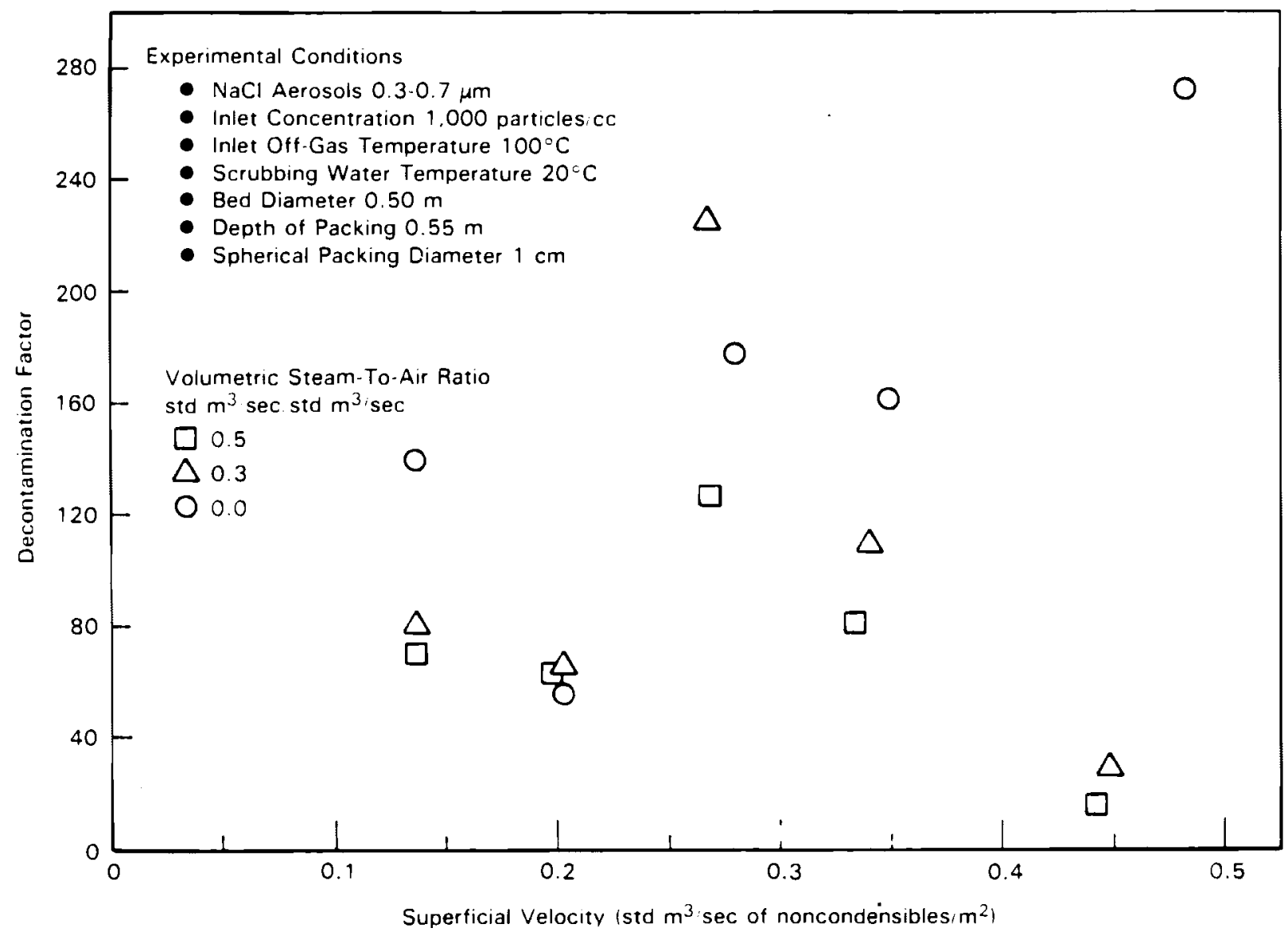

FIGURE 5. Design Information for Sizing the SBS Bed Cross-Sectional Area Based on Soluble Aerosols

Superficial velocities below $0.14 \mathrm{~m} / \mathrm{sec}$ were not investigated, because unstable gas flow was encountered below this velocity. No attempts were made to ensure even gas distribution. Based on the smaller plexiglass model, it appears that superficial velocities greater than $0.14 \mathrm{~m} / \mathrm{sec}$ lead to a gas bubble that covers almost the entire bed cross-sectional area before collapsing to allow water to flow up through the bed. This pulsation occurs at all flow rates. Once the velocity fell below $0.14 \mathrm{~m} / \mathrm{sec}$, the bubble would completely disappear so that there was no off-gas flow at all for short periods of time. This pulsation is evidence of poor gas distribution.

This pulsing gas flow can be overcome by drilling holes in the bed retaining walls just above the packing support plate. The water can then circulate freely without having to compete for the same bed cross-sectional area with the 
gas. This configuration is similar in principle to the operation of a bubble column with a draught tube (Miyahara et al. 1986). This concept was tested in the plexiglass model. A perforated distribution plate was used, located below the packing, instead of a wire mesh screen. At all flow rates investigated, a stable gas bubble was formed that covered the entire bed cross-sectional area. This flow configuration completely eliminated the gas pulsation, making it possible to cover a wider velocity range. This design modification was not tested for aerosol collection performance, but would be expected to be more efficient at low flow rates, and equivalent at high flow rates.

Influence of Re-Entrainment on Scrubbing Performance. The results shown in Figures 4 and 5 are for ideal conditions in which there has been no accumulation of captured material in the scrubbing solution. During operation, large amounts of make-up water may have to be added to maintain the overflow purge at a rate sufficient to minimize the concentration of captured material. This mode of operation is unrealistic in most applications, especially in the HLW processing industry, where the increased volume of scrubbing liquor has to be treated as low-level waste. As the concentration of captured material builds up in the scrubbing solution, the amount of material re-entrained into the off gas will increase. The SBS can actually be used as an aerosol generator if the concentration and flow rate are high enough.

A certain amount of the scrubbing solution will be entrained in the off gas as the bubbles burst at the surface of the scrubbing solution. The number and size of droplets entrained are a function of the flow rate of the off gas. The amount of material actually lost due to re-entrainment at any given velocity is a function of the concentration of captured aerosols. Maintaining a low concentration of captured aerosol limits the amount of material that is re-entrained.

Experiments were conducted to determine the influence of superficial velocity and scrubbing-solution concentration on performance by adding either sodium chloride or titanium dioxide to the scrubbing solution. Room air was then drawn through the SBS and the outlet concentration was measured. The 
inlet aerosol concentration due to material present in the room air was insignificant, so the outlet concentration represented aerosols originating from the scrubbing liquor.

The results are shown in Figures 6 and 7 . Figure 6 shows the outlet concentration as a function of the concentration of the material in the scrubbing solution. The outlet concentration resulting from re-entrainment increases exponentially with sodium chloride concentration. The re-entrained aerosol concentration also increases rapidly with concentration for titanium dioxide (concentration of suspended $\mathrm{TiO}_{2}$ ). An explanation as to the shape and relative locations of the curves in Figure 6 is given by Ruecker and Scott (1986). The addition of $36 \mathrm{~kg}$ of titanium dioxide to the approximately $650 \mathrm{~L}$ of scrubbing solution in the SBS only resulted in a suspended solids concentration of $3.8 \mathrm{~g} / \mathrm{L}$. This solids loading should be typical of concentrations encountered during long-term operation of an SBS. The sodium chloride concentrations investigated represent the concentration range of total soluble material under which re-entrainment does not severely hamper the scrubbing performance. The degree of re-entrainment should also increase with velocity, because the off gas will have more energy available to shear off droplets of scrubbing solution. This result is what is seen in Figure 7. Limiting the superficial velocity and the scrubbing-solution concentration will help to improve the scrubbing performance by limiting the amount of captured material that is re-entrained into the off gas.

The ability of Dow defoamer DB-110A® to almost completely eliminate re-entrainment, as discussed in Section 3.2, is important for two reasons: it improves the scrubbing performance of the SBS, and it also allows higher captured aerosol concentrations in the scrubbing liquor, which is favorable from a process point of view. It cannot be assumed that DB-110A will work for all applications. Therefore, it is desirable to design the bed using Figures 6 and 7 to estimate how re-entrainment at a specific scrubbing-solution concentration will lower the design curve shown in Figure 4. There is some concern that $D B-110 A^{\circ}$ may be decomposed by the radiation emitted during HLW processing. The acidic nature of the scrubbing solution, caused by the presence of $\mathrm{NO}_{2}$ and halogens in the off gas, could also be detrimental to the defoamer. 


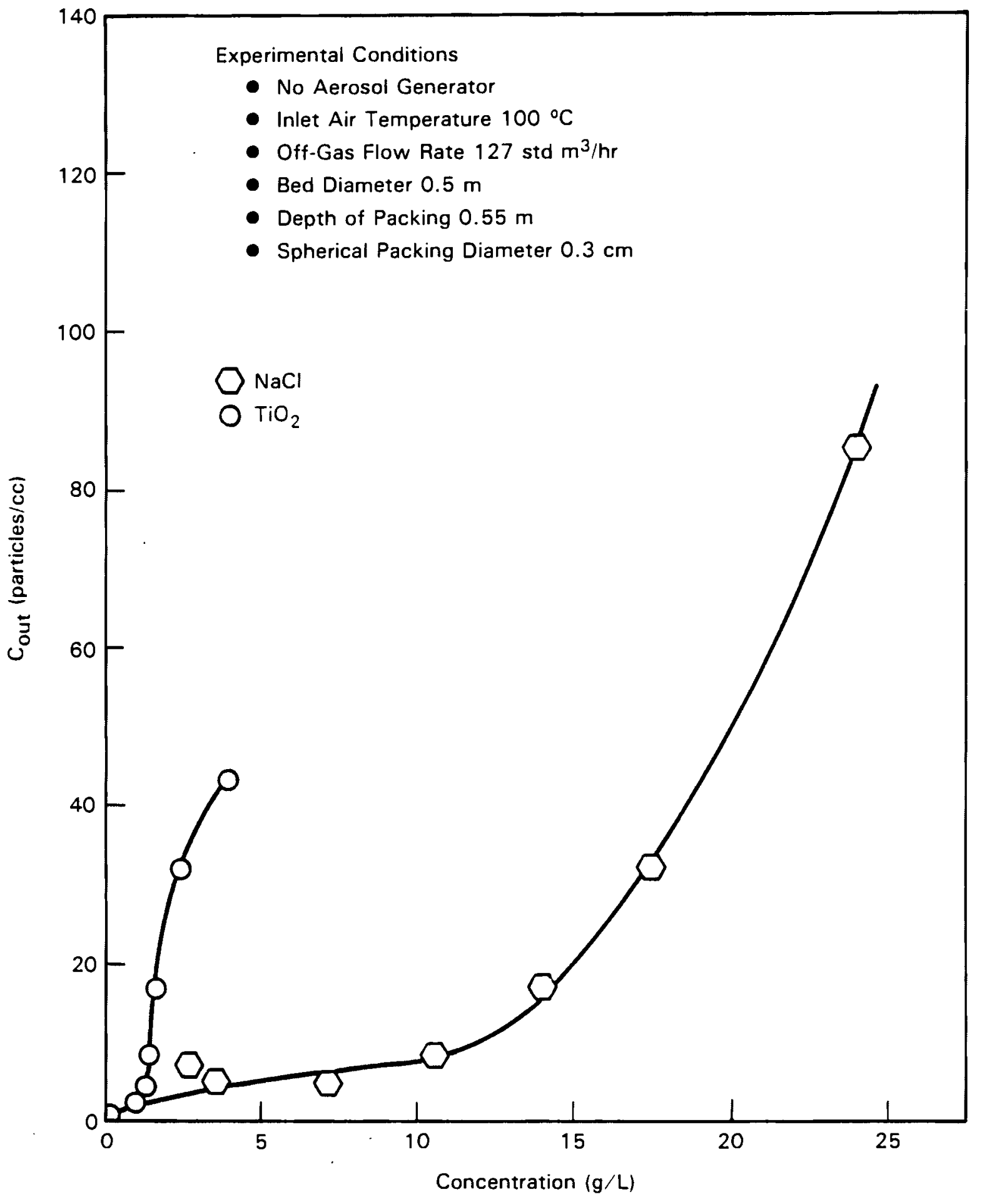

FIGURE 6. Re-Entrainment as a Function of Scrubbing Solution Concentration

4.7 


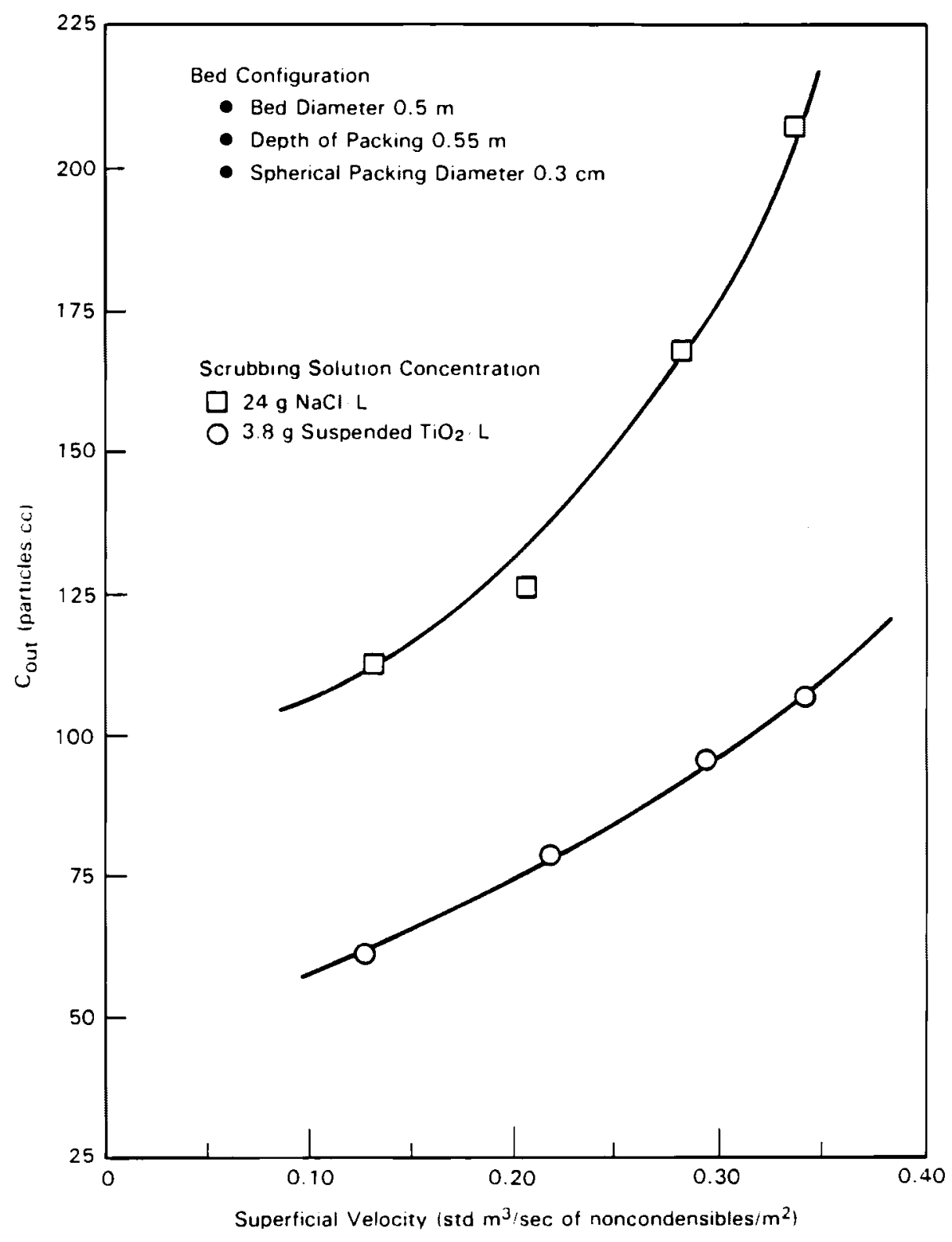

FIGURE 7. Influence of Velocity on Re-Entrainment

More tests are needed using DB-110A to determine whether its decomposition rate is too fast to economically use the defoamer with melter of gas.

\subsection{COOLING COILS}

Heat transfer information was recorded during the SBS studies of Ruecker and Scott (1986). The cooling-water flow rate, inlet and outlet temperature of the cooling water, and the bulk scrubbing solution temperatures above and below 
the cooling coils were measured so that overall heat transfer coefficients could be determined for the stainless-steel helical cooling coils in the annular region of the SBS. Equation (1) was used to determine the heat removed from the reservoir by the cooling coils.

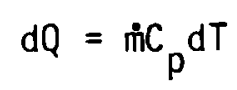

were: $Q=$ heat transfer rate, $W$

$$
\begin{aligned}
\dot{m} & =\text { mass flow rate of water, } \mathrm{kg} / \mathrm{h} \\
\mathrm{C}_{\mathrm{p}} & =\text { specific heat, } \mathrm{KJ} / \mathrm{kg} \cdot{ }^{\circ} \mathrm{C} \\
T & =\text { temperature, }{ }^{\circ} \mathrm{C}
\end{aligned}
$$

This value then enabled the overall heat transfer coefficient to be calculated from the log mean temperature difference and the external surface area available for heat transfer, Equation (2).

$$
U .=Q / A \Delta T_{L M}
$$

where: $\quad U=$ overall heat transfer coefficient, $W / m^{2} .{ }^{\circ} \mathrm{C}$

$$
\begin{aligned}
A & =\text { external surface area, } \mathrm{m}^{2} \\
\Delta T_{L M} & =\log \text { mean temperature difference, }{ }^{\circ} \mathrm{C}
\end{aligned}
$$

The resulting values from several tests are shown in Table 1. The SBS used for these experiments had two independent coils that were not always used concurrently. The data show that approximately the same value was achieved for both coils. For design calculations, a conservative value of $575 \mathrm{w} / \mathrm{m} 2 \cdot{ }^{\circ} \mathrm{C}$ is recommended because long-term usage will lower the heat transfer coefficient as scale builds up on the tubing walls. 
TABLE 1. Experimentally Determined Values of the Overall Heat Transfer Coefficient, $U\left(\mathrm{~W} / \mathrm{m}^{2} \cdot{ }^{\circ} \mathrm{C}\right)$

\begin{tabular}{ccc} 
Run \# & Coil \#1 & Coil \#2 \\
\cline { 2 - 3 } 5 & $-(\mathrm{a})$ & 761 \\
6 & - & 886 \\
9 & 1380 & - \\
17 & 778 & - \\
18 & 1062 & - \\
20 & 863 & - \\
21 & 994 & - \\
24 & 715 & - \\
25 & 750 & - \\
27 & 710 & - \\
29 & 744 & - \\
31 & 761 & - \\
32 & 926 & - \\
48 & - & 942 \\
51 & - & 647 \\
52 & - & 857 \\
56 & 1084 & 1056 \\
59 & - & 903 \\
61 & 852 & 960 \\
62 & - & 954 \\
64 & 1317 & 874 \\
65 & 1175 & 1090 \\
68 & 1175 & 1107 \\
69 & 1306 & 1113 \\
71 & 1033 & 1136 \\
\hline Avg & $979 \pm 224 \mathrm{~W} / \mathrm{m}^{2} \cdot{ }^{\circ} \mathrm{C}$ & $\pm 143 \mathrm{~W} / \mathrm{m}^{2} \cdot{ }^{\circ} \mathrm{C}$
\end{tabular}

(a) Not used during this run. 


\subsection{SBS DESIGN SEQUENCE}

The dimensions of the SBS are determined from the inside out. First the inlet pipe is sized, then the insulation thickness around the inlet pipe is determined. A sleeve is chosen to house the inlet pipe, thus completing the downcomer assembly. The diameter of the packed bed wall is determined by the cross-sectional area necessary to achieve the desired scrubbing performance. The diameter of the reservoir tank is determined by the number of cooling coils needed in the annular region.

\subsection{SIZING THE INLET PIPE}

The inlet pipe must be sized such that it will not be susceptible to plugging. The choice of appropriate sizing criteria depends on the nature of the off gas. If the SBS will be used as part of an existing off-gas system that has not experienced excessive accumulation of particulate material, the same size pipe (or smaller) should be used for the inlet line. For new applications, the inlet pipe should be sized for a gas velocity of $18 \mathrm{~m} / \mathrm{s}$ or greater. The inside pipe diameter (d), in meters, can then be calculated using Equation (3).

$$
d_{i}=\sqrt{\frac{4}{\pi} \frac{F}{V}}=0.000443 \sqrt{F}
$$

where $F$ is the volumetric off-gas flow rate in actual cubic meters per hour.

For situations in which the off gas contains extremely high aerosol concentrations, it may be desirable to decrease the size of the inlet pipe below that determined by Equation (3). If the aerosols are sticky (droplets of heavy oil, molten glass, etc.), a steam film cooler can be incorporated in the SBS inlet line to prevent plugging. An example of this modified downcomer assembly is shown in Figure 8. Film coolers have been successfully used to prevent plugging from occurring in the exit line from ceramic melters (Randall and Sabatino 1986). Steam is recommended because it is a condensible gas. Air can be used in the film cooler, although it will necessitate a larger SBS to 


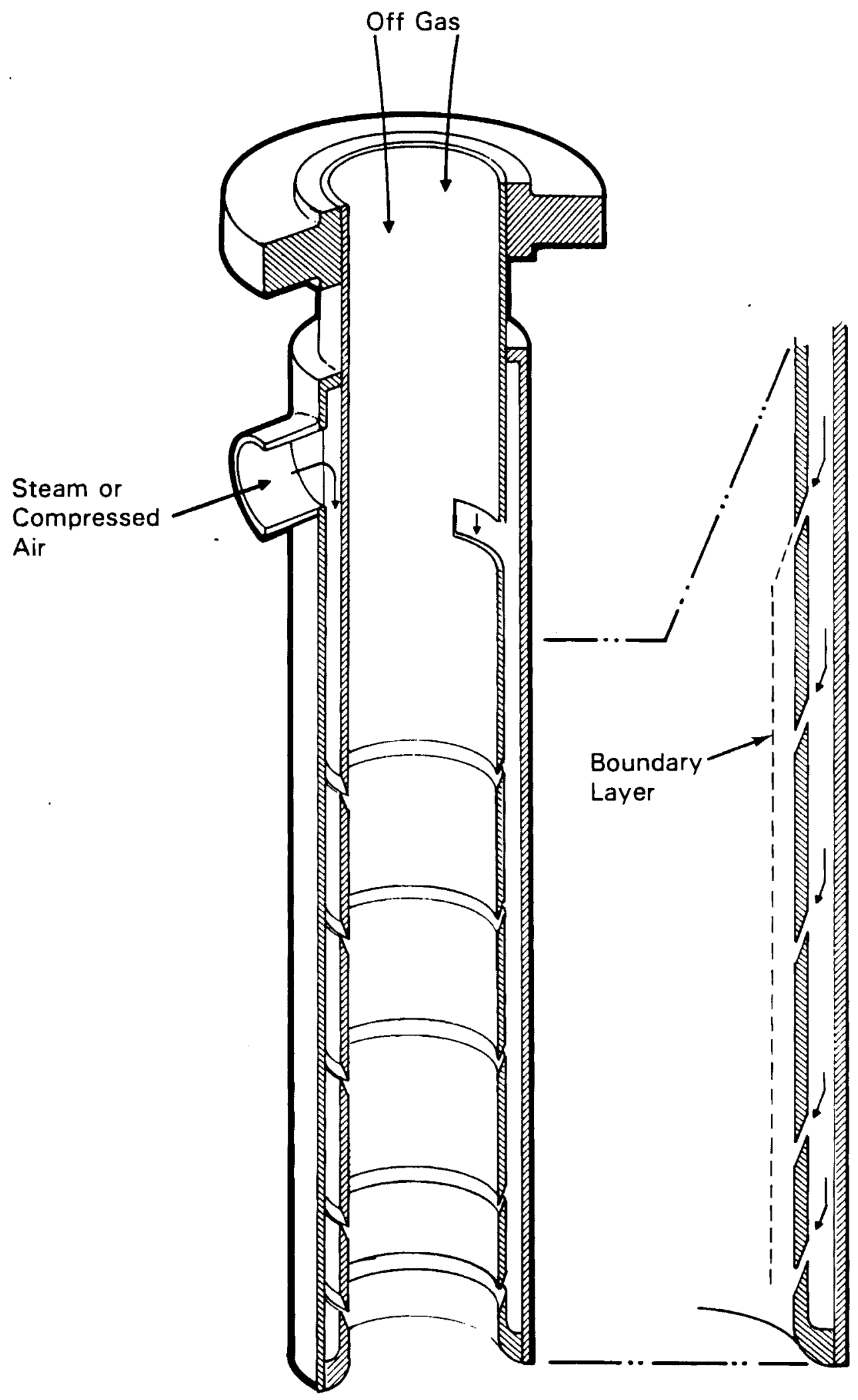

FIGURE 8. Film Cooler Cross-Section Details 
achieve the same scrubbing efficiency. Abrupt changes in the direction of offgas flow should be avoided between the location where the aerosols are being formed and the SBS to minimize the deposition of aerosols in the pipe. For nuclear waste processing in particular, long-radius bends should be used on the SBS inlet piping.

\subsection{DETERMINATION OF THE INSULATION THICKNESS AROUND THE SBS INLET PIPE}

The off gas from a liquid-fed ceramic melter may contain a significant amount of water. If the inlet pipe to the SBS is not insulated, premature cooling of the off gas can occur in the downcomer assembly. It is possible to lower the off-gas temperature below its dew point, resulting in the condensation of steam on the inlet pipe walls. The wetted pipe wall may promote deposition of material that could potentially result in a plugged line. It is also desirable to prevent gases from condensing to avoid corrosion. The off gas from melters that process nuclear waste may contain acid gases which can attack the pipe, decreasing its lifetime.

Off-gas systems are generally required to handle varying duties. The thickness of the insulation that thermally. separates the scrubbing solution from the off gas should be determined by the operating conditions that are closest to the off-gas dew point. The minimum insulation thickness can then be determined by calculating the heat transfer rate necessary to cool the off gas to its dew point. Estimates of the dew-point temperature for a gas mixture can be obtained using correlations presented by Reid, Prausnitz and Sherwood (1977). The minimum heat transfer rate required to cool the off gas is calculated by integrating Equation (4) from the inlet temperature to the dew-point temperature,

$$
Q=\dot{m} g \int_{T_{\text {inlet }}}^{T_{p} d e w \text { point }} c_{p}
$$

Values for the specific heat can be found for many gases in the Chemical Engineers' Handbook (Perry and Green 1984). An average value for the specific 
heat may not be accurate enough if the temperature difference is large. Equations for the specific heat as a function of temperature for various gases are given by Smith and Van Ness (1975). The maximum acceptable overall heat transfer coefficient can then be calculated from Equation (2). The overall heat transfer coefficient can be written as a sum of resistances to heat transfer as shown in Equation (5) Holman (1981).

$$
\frac{1}{U}=\frac{1}{h_{i}}+\frac{1}{h_{0}}+\left(\frac{x}{k}\right)_{\text {insul }}+\left(\frac{x}{k}\right)_{\text {inside wall }}+\left(\frac{x}{k}\right)_{\text {sleeve }}
$$

were: $\quad U=$ overall heat transfer coefficient, $\mathrm{W} / \mathrm{m}^{2} \cdot{ }^{\circ} \mathrm{C}$

$$
\begin{aligned}
& n_{i}=\text { inside heat transfer coefficient, } \mathrm{w} / \mathrm{m}^{2} \cdot{ }^{\circ} \mathrm{C} \\
& n_{0}=\text { outside heat transfer coefficient, } \mathrm{w} / \mathrm{m}^{2} \cdot{ }^{\circ} \mathrm{C} \\
& \mathrm{x}=\text { material thickness, } \mathrm{m} \\
& \mathrm{k}=\text { thermal conductivity, } \mathrm{w} / \mathrm{m}^{2} \cdot{ }^{\circ} \mathrm{C}
\end{aligned}
$$

A conservative estimate of the insulation thickness can be obtained by ignoring the resistances to heat transfer in the pipe walls and the fluid films at the inside and outside walls. The minimum amount of insulation can then be determined by Equation (6), provided the thermal conductivity of the insulating material is known.

$$
\frac{1}{U}=\left(\frac{x_{\min }}{k}\right)_{\text {insul }}
$$

The insulation thickness required is generally quite small. Care must be taken in fabrication to ensure that no water can leak into the annular area that houses the insulation, or else the heat transfer rates will greatly increase.

The diameter of the outer sleeve of the downcomer assembly is only important to the design of the SBS in that it affects the overall diameter of the bed. The larger the diameter of the downcomer assembly, the larger the bed diameter will have to be to have the same cross-sectional area for flow. In Section 3.1 it was mentioned that it is desirable to have condensation occur in the inlet pipe; yet, a procedure has just been outlined to determine the amount 
of insulation necessary to prevent premature cooling of the off gas. The explanation of this apparent contradiction is that the condensing gases should be cooled in a manner that promotes condensation on the aerosols. This result will not occur if the pipe walls are cold; the gases will condense on the cold pipe, which can lead to plugging. One way of cooling the gas and preventing deposits from forming on the pipe walls may be to use a film cooler concept in the design of the downcomer assembly as shown in Figure 8.

\subsection{SIZING THE BED CROSS-SECTIONAL AREA}

Because so many parameters influence the scrubbing efficiency of the SBS, it is impractical to generate a family of design curves that will apply for any set of inlet conditions. It is therefore more useful to consider practical size limitations on the bed diameter. The design engineer must then decide whether or not the expected DF will be acceptable based on the information presented in Chapters 3 and 4.

The size of the bed is generally limited by either the overall dimensions of the SBS or by the effectiveness of the distribution plate. The high cost of floor space in a radioactive containment cell limits the overall size of the SBS when it is used for processing HLW. For more traditional industrial applications, the controlling factor in determining the maximum bed diameter for an SBS is the ability of the distribution plate to adequately distribute the off gas over the entire cross-sectional area (see Appendix A for distribution plate design information). Even if the gas distribution is ideal, once a certain point is reached, a larger bed diameter has no advantage because the bed velocity of the off-gas bubble will reach a minimum; only the frequency of bubble formation will decrease. The real objective when designing an SBS is to size the bed and the inlet distribution plate such that the resulting bubbles are as small as possible and the residence times as long as possible. The small bubbles lead to shorter transport distances; the longer residence times allow more time for the aerosols to diffuse the necessary distance to the collecting media.

Superficial velocities in the packed bed above $0.3 \mathrm{~m} / \mathrm{sec}$ are typically undesirable because of the resulting re-entrainment. Higher velocities will 
not be practical unless defoamers can economically be used to minimize re-entrainment. Superficial velocities below $0.15 \mathrm{~m} / \mathrm{sec}$ are impractical unless holes are used in the side of the packed bed so that the off gas and circulating water do not compete for the same cross-sectional area. With such holes, a lower stable superficial velocity of $0.05 \mathrm{~m} / \mathrm{sec}$ can be attained.

Decontamination factors for soluble aerosols can be estimated by determining the steady-state concentration of captured soluble aerosol in the scrubbing-solution. Because the scrubbing performance has been shown to be limited by re-entrainment for soluble aerosols, the outlet concentration can be assumed to be made up entirely of re-entrained aerosols. The re-entrained aerosol concentration can be estimated from Figures 6 and 7 based on the design velocity of noncondensible gases at standard conditions and the estimated scrubbing-solution concentration. The DF is then approximately equal to the inlet concentration, $C_{i n}$, (set in the design specifications) divided by the re-entrained outlet concentration, $C_{\text {out }}$ :

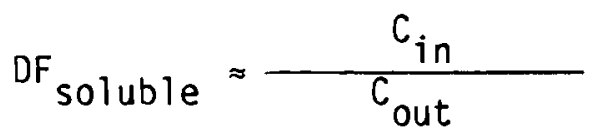

Estimating the DF for the insoluble aerosols is more involved and less accurate, because the capture efficiency is not limited by re-entrainment. Particles larger than 10 microns can be assumed to be removed at essentially $100 \%$ efficiency. Figure 4 can then be used to predict the DF for particles less than 10 microns. The value obtained from Figure 4 is an ideal DF (DF*), because the curves were developed using clean scrubbing solution, which would eliminate re-entrainment losses. The DF can be corrected for re-entrainment by estimating the suspended-solids concentration in the scrubbing liquor at steady state. The re-entrained outlet concentration can then be estimated for insoluble material from the titanium dioxide curves shown in Figures 6 and 7 . The corrected DF would then be calculated by Equation (8).

$$
D F_{\text {insoluble }} \approx \frac{C_{\text {in }}}{\left(\frac{C_{\text {in }}}{D F^{\star}}\right) d_{p}<10+C_{\text {out }}}
$$


Equations 6 and 7 will provide estimates to determine if the assumed superficial velocity will provide acceptable results. More involved estimates of DF* for insoluble material can be obtained from the correlation presented by Ruecker and Scott (1986). This correlation should be used with extreme caution when extrapolating out of the range of independent variables investigated. Methods for improving the DF for insoluble aerosols can be found in Section 3 .

The previous discussion was geared toward the design of an SBS for general industrial applications. However, the experimental tests conducted by Ruecker and Scott (1986) were designed to size an SBS specifically for use with liquidfed ceramic melters for HLW reprocessing. In this application, the only aerosols of real concern are those that are radioactive. These aerosols usually come in two forms: large particles that are easily captured, or submicron aerosols that are not. Cesium and ruthenium are the radionuclides of primary importance (Kitamura et al. 1986). Cesium aerosols are generally water soluble; their DF is easily estimated from Equation (7). Ruthenium aerosols are insoluble, and are usually present in the form of ruthenium dioxide. The titanium dioxide results presented in figure 4 were shown to be representative of ruthenium dioxide behavior by Ruecker and Scott (1986). Figure 4 can then be directly used to determine the ideal ruthenium DF. A corrected estimate can be obtained using Figures 6 and 7 to estimate $C_{\text {out }}$, and Equation (8).

\subsection{VERTICAL BED DIMENSIONS}

Depth of Packing. No experiments were performed in which the packing height was varied. The results shown in Figures 4 and 5 were based on a bed height of $0.55 \mathrm{~m}$. The results of Hilliard, McCormack and Postma (1981) were based on a packing height of $0.61 \mathrm{~m}$. Spherical packing is generally used because it is less likely to plug as a result of accumulated solids.

Various packing heights were not investigated because of the difficulty associated with modifying the bed of the SBS to maintain a reasonable water level above the packing. There are practical limitations on the depth of packing to use, especially for use with melters, because a blower must be used to induce the off-gas flow through the SBS. Assuming that the packing is completely covered by water, the pressure drop across the SBS, in inches of 
water, is at least equal to the submergence of the downcomer assembly. The additional pressure drop associated with beds much deeper than $0.6 \mathrm{~m}$ quickly becomes impractical. The depth of the water above the gas inlet must be at least $0.3 \mathrm{~m}$ to reasonably quench the off gas during processing of high-level waste.

Upper Skirt. An upper skirt is not necessary from an operational point of view. A holddown screen should be placed directly on top of the packing to prevent the bed from becoming fluidized. Scrubbing efficiency will decrease as the bed fluidizes, as well as cause unnecessary attrition of the packing.

Lower Skirt. The size of the bubble underneath the packing reflects the pressure drop due to flow through the bed and gas distribution plate. The pressure drop due to the packing in the bed will be negligible for a properly designed SBS, although a significant pressure drop can arise due to the distribution plate. A $0.23 \mathrm{~m}$ lower skirt is probably sufficient to handle the pressure drop through most beds, including the gas distributor, and still leave extra room to handle any unexpected off-gas surges. To achieve an even distribution across the packing, generally a pressure drop must be incurred across the inlet plate, or a detectable pressure drop through the bed due to flow.

Water Level. The choice of the water level is governed by the available pressure drop, gas cooling duty and aerosol collection. Re-entrainment would probably be increased if the water level was maintained at the top of the packing. The off-gas velocity will decrease in the water layer above the packing, reducing the re-entrainment. Terminal bubble velocities should be attained quickly (within the first $0.15 \mathrm{~m}$ ), so there is no advantage gained by increasing the water level except for some scrubbing that would occur. Any increase in the DF at this point would probably not be justified by the increase in pressure drop. A water layer above the packing is necessary to help quench the off gas if the inlet temperature is very high.

Figure 9 shows the axial temperature profile for a typical SBS test. The off gas does not reach the scrubbing-solution temperature until a few inches above the packing, even for a mild inlet temperature of $100^{\circ} \mathrm{C}$. The data reported by Hilliard, McCormack and Postma (1981) support the prediction that the degree of re-entrainment does not change significantly with water level. 


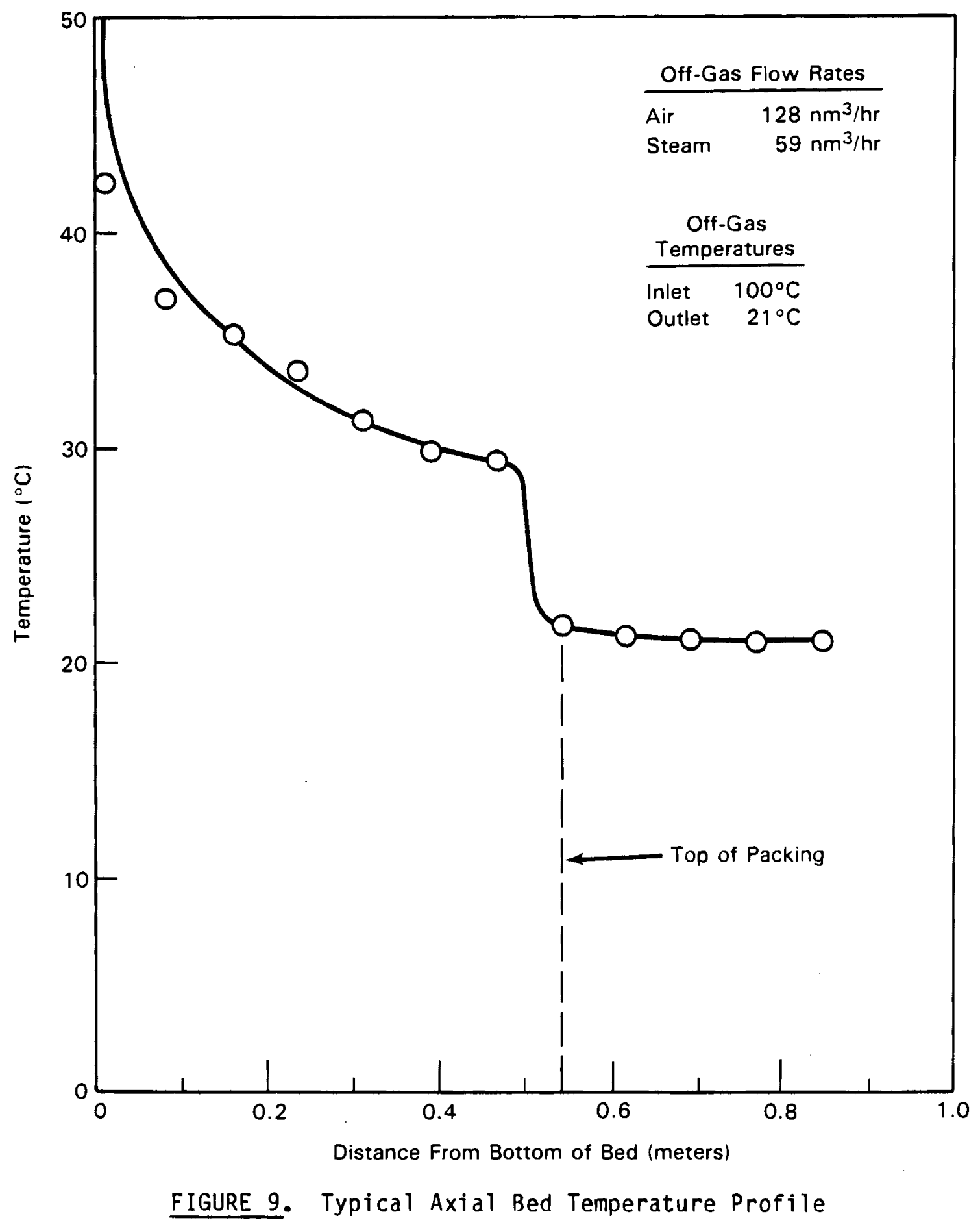


In their experiments, the water level had no measurable effect on performance until it dropped below the top of the packing. At that point, the aerosol scrubbing performance began to drop.

Disengagement Height. Wu (1984) suggests a disengagement height of $0.2 \mathrm{~m}$ for impingement drum separators operated at 12 psia. The disengagement height in an SBS can be expanded as necessary to provide working room between the lid of the SBS and the top of the bed. This may be desirable for filling the bed with packing. This added height will probably not significantly reduce re-entrainment.

\subsection{SIZING THE COOLING COILS}

The SBS is intended to quench off gas as well as serve as the primary scrubber in the off-gas system. The scrubbing-solution reservoir provides an adequate thermal sink for handling surges of hot off gas. The heat must then be transferred out of the aqueous pool using cooling coils. Typically, independently wound helical coils are located in the annular region of the SBS. The cooling coils have to this point been constructed of stainless steel tubing. Several heat transfer experiments have been conducted with a pilot-scale SBS to determine the overall heat transfer coefficient for this material under moderate flow conditions on the outside of the cooling coils.

Determination of Cooling Duties. The heat transfer rate was based on a heat balance around the cooling coil. The heat transfer rate to the cooling water can be determined from Equation (1). The inlet conditions leading to the highest heat transfer requirements should be used as a basis for sizing the cooling coils. Heat transfer rates to the cooling water can also be determined without any knowledge about the cooling water temperatures or flow rate, by performing a heat balance around the SBS. This procedure was followed for experiment \#59 in Table 1. The resulting heat transfer rate was within $8 \%$ of the heat transfer rate that was obtained based on a heat balance around the cooling coils.

Normally there exists an upper limit as to the allowable outlet cooling water temperature and a specified inlet temperature. This makes the surface area of the cooling coils the only parameter left to vary to ascertain the 
desired heat transfer rates. The heat transfer requirements for the specific off gas must then be determined to size the cooling coils. Some typical assumptions when determining the heat transfer requirements of the of $f$ gas are listed below:

- Radiant and conductive heat losses to the surroundings are neglected.

- The phases in the system are steam, liquid water and air.

- Heats of chemical reaction and mixing are neglected.

- Heat from chemical reaction and mixing is neglected.

- Heat from agitation, jet transferring and friction (from moving gas through the bed) is neglected.

- The exit off gas is in equilibrium with the scrubbing solution.

It is important to include the contributions to the heat transfer requirements due to decay heat when dealing with off gas generated during high-level waste processing, because significant levels of radioactive material can build up in the scrubbing solution. The amount of heat generated by the decaying material present in the scrubbing solution can be as large as the heat added by the incoming off gas in some instances.

The scrubbing-solution temperature above the coils should be the same as the exit off-gas temperature. It is easiest to specify the scrubbing-solution temperature and size the coils based on this value. If the off gas is not sufficiently cooled, the overflow nozzle can be moved up as necessary, thus increasing the volume of water above the packing. A conservative estimate of the $\log$ mean temperature difference would be to assume that the scrubbing-water temperature does not change at all as it passes over the cooling coils. Under normal melter operating conditions, the temperature difference should be less than $5^{\circ} \mathrm{C}$.

Cooling Coil Design. Concentric independent helix cooling coils made of 2.0 to 2.5-cm-diameter stainless steel tubing are recommended. A radial spacing of approximately $8 \mathrm{~cm}$ should be maintained between the cooling coils. If the bed has a $0.5-m$ diameter, the first cooling coil should have a $0.66-m$ diameter, and so on until enough surface area has been added to accommodate the 
required heat transfer. The same spacing should be maintained between the outer-most coil and the outside wall of the SBS unless more room is needed to run piping along the inside wall of the SBS. The heat transfer coefficient presented here was based on 1.9-cmi-diameter SS tubing coiled at a center-to-center pitch of $6.4 \mathrm{~cm}$. The inlet and outlet nozzles of the cooling coils should exit the SBS above the water level. The same is true for any other nozzles penetrating the exterior wall of the SBS to limit the potential hazards associated with faulty welds. The surface area of a helix cooling coil, A, can be calculated using Equations (9) through (11).

$$
\begin{gathered}
h=N p \\
L=N \sqrt{(\pi d)^{2}+(p)^{2}} \\
A=\pi d_{0} L
\end{gathered}
$$

were: $\quad N=$ number of turns, dimensionless

$p=$ center-to-center pitch, $m$

$h=$ height of the coil, $m$

$d=$ diameter of helical cooling coil, $m$

$L=$ straight length of coil, $m$

$\mathrm{d}_{0}=$ outside tube diameter, $m$

The number of turns is determined by the allowable height of the coil. There is no point in having any of the cooling coil above the water level. The length of the coil can then be determined using Equation (10), followed by the external surface area, Equation (11). It is important to remember that as more coils are added, the size of the tank will increase, resulting in a larger aqueous pool. The increase in water will be accompanied by an increase in decay heat if the off gas contains radioactive material, as is the case with melter-generated off gas. The cooling-coil sizing procedure then becomes an iterative process. As each coil is added, the radioactive material in the extra volume of water must be accounted for. The designer must verify that the current coil design can remove the heat generated by the waste. 
Minimum Cooling Water Flow Rate at Maximum Heat Transfer Conditions. The minimum cooling water flow rate can be determined by using Equation 1. The temperature difference is just the maximum allowable outlet cooling water temperature minus the inlet cooling water temperature. The maximum heat transfer rate has already been calculated. The mass flow rate of the water is the only unknown parameter. The pump can then be sized using this water flow rate as a minimum upper limit. Pressure drops as a function of water flow rate through stainless steel tubing can be found in the Swagelok Tube Fitting and Installation Manual (Callahan 1985). The pressure drops given are for straight lengths of pipe. The true length of the coiled tubes can be converted to equivalent straight lengths by using a conservative multiplier of 1.5 . The resulting pressure drop information will assist the design engineer in selecting the appropriate pump. 
.

$\ell$ 


\subsection{CONCLUSIONS}

Three key areas must be considered when designing an SBS: 1) the characteristics of the inlet off gas, 2) the hydrodynamics of the off gas as it flows through the bed, and 3 ) the re-entrainment of scrubbing solution into the exiting off gas. In addition, certain design modifications can reduce maintenance requirements as well as simplify SBS operation.

\subsection{OFF GAS CONDITIONING}

The performance of the SBS will depend on the characteristics of the incoming of $f$ gas. Sometimes the characteristics can be adjusted prior to the off gas entering the SBS, which is more conducive to the effective capture of aerosols. The important adjustable parameters are listed below.

- Aerosol collection improvements can be obtained by reducing the flow rate of noncondensible gases. This adjustment can be achieved in the HLW processing industry by limiting inleakage into the of $f$-gas treatment system. This will lead to a longer off-gas residence time in the bed, and may reduce the required size of the bed. Also, the inlet particle concentration will be higher, which will enhance the aerosol capture performance due to Brownian coagulation.

- A high steam-to-air ratio in the inlet gas will enhance the aerosol capture performance within the bed. Steam was found to improve the DF of insoluble aerosols from 8 at a steam-to-air ration of 0 , to 12 at a ratio of 0.5 . Flux force/condensation is responsible for this effect.

- Injecting a cold vapor into the inlet gas will force steam to condense on the aerosols, making them effectively larger and easier to capture. This process has led to improvements in the DF from 12 when steam is condensed within the bed to as high as 60 for insoluble aerosols. 


\subsection{HYDRODYNAMICS}

The hydrodynamics of the off gas as it flows through the bed are very important in determining aerosol removal performance. The bed of the SBS should be sized to produce as small a bubble as possible, while maintaining a uniform gas distribution. The smaller the off-gas bubbles within the bed, the shorter the transport distances to the collecting media and the longer the residence time.

- Small bubbles of a particular size cannot necessarily be achieved simply by using a gas distribution plate made of tiny holes. A point will be reached where the size of the orifice will no longer influence the size of the bubbles. The size will be determined solely by the physical properties of the gas and liquid.

- The packing in the bed helps to prevent the bubbles from agglomerating. However, small packing will not prevent channeling if the interstitial packing volume is not large enough for distinct bubbles to form.

\subsection{RE-ENTRAINMENT}

Another important aspect in determining the overall performance of the SBS is the re-entrainment of aerosols from the scrubbing solution.

- Re-entrainment can be limited by lowering the superficial velocity of noncondensible gases and/or reducing the captured aerosol concentration in the scrubbing solution.

- The scrubbing solution concentration can be controlled by condensing more steam or injecting makeup water into the reservoir to maintain the desired purge rate through the overflow line.

- Defoamer may be useful in limiting re-entrainment, even for concentrated scrubbing solutions, by lowering the surface tension at the interface between the scrubbing solution and the void space above the pool. A defoamer has been used to decrease re-entrainment from 140 particles/cc to 19 particles/cc. 


\subsection{DESIGN MODIFICATIONS}

Various design options can minimize the maintenance requirements of the SBS:

- The inlet to the overflow line, or the stilling well, can be extended down into the reservoir of the SBS to withdraw the liquid containing the heavier material instead of removing the overflow solution from the surface of the pool. This modification will minimize the settling of solids in the bottom of the SBS.

- Holes can be drilled in the side of the bed-retaining wall just above the distribution plate so that the liquid circulating through the bed does not compete for the same bed cross-sectional area as the incoming off gas. This modification will lead to more stable gas flow characteristics, particularly at low rates.

- It may be possible to incorporate a film cooler in the inlet line to prevent the deposition of solids on the inside pipe wall, as well as to inject steam into the off gas. Steam or a cold vapor (if necessary) can be used in the film cooler to cause the steam to condense on the aerosols. This process will make the aerosols larger and easier to capture.

The SBS is ideal for HLW processing applications for three reasons: 1) it effectively removes large aerosols, as well as a significant fraction of the aerosols in the hard-to-capture size range $(0.1$ to $1.0 \mu \mathrm{m}), 2)$ it can easily quench the hot off gas, and 3 ) it is a passive system with no moving parts and high reliability. A properly sized SBS can achieve DFs of greater than 100 even for aerosols in the 0.3 to $7.0 \mu \mathrm{m}$ size range if the characteristics of the off gas are suitable. Although the SBS has been used almost exclusively for $H L W$ processing, it is versatile enough to be used in other, more traditional off-gas cleaning applications. 
$\checkmark$ -
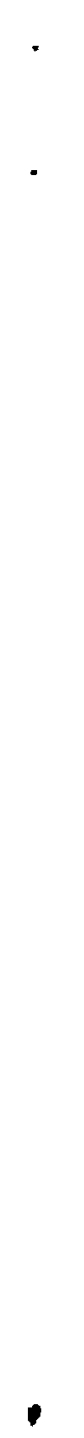


\subsection{NOMENCLATURE}

A

$C_{\text {in }}$

$c_{\text {out }}$

$\mathrm{C}_{\mathrm{p}}$

d

$\mathrm{d}_{\mathrm{i}}$

$d_{0}$

DF

$F$

$h$

$h_{i}$

$\mathrm{h}_{0}$

k

L

$\dot{\mathrm{m}}$

$\dot{\mathrm{m}}_{\mathrm{g}}$

N

p

Q

T

$\Delta T_{L M}$

U

v

$x$

External surface area, $\mathrm{m}^{2}$

Inlet aerosol concentration, particles $/ \mathrm{cm}^{3}$

Outlet aerosol concentration due to re-entrainment, particles $/ \mathrm{cm}^{3}$

Specific heat, $\frac{\mathrm{kJ}}{\mathrm{kg} \cdot{ }^{0} \mathrm{C}}$

Diameter of helical cooling coil, m

Inside pipe diameter, $m$

Outside pipe diameter, $m$

Decontamination factor, dimensionless

Volumetric flow rate, $\mathrm{m}^{3} / \mathrm{hr}$

Height of the cooling coil, m

Inside heat transfer coefficient, $\mathrm{W} / \mathrm{m}^{2} \cdot{ }^{\circ} \mathrm{C}$

Outside heat transfer coefficient, $\mathrm{W} / \mathrm{m}^{2} \cdot{ }^{\circ} \mathrm{C}$

Thermal conductivity, $\mathrm{w} / \mathrm{m}^{2} \cdot{ }^{\circ} \mathrm{C}$

Length of tubing used to make cooling coil, m

Mass flow rate of water, $\mathrm{kg} / \mathrm{h}$

Mass flow rate of off gas, $\mathrm{kg} / \mathrm{h}$

Number of turns used to make cooling coil, dimensionless

Center-to-center pitch of cooling coil, m

Heat transfer rate, $w$

Temperature, ${ }^{\circ} \mathrm{C}$

Log mean temperature difference, ${ }^{\circ} \mathrm{C}$

Overall heat transfer coefficient, $\frac{W}{m^{2} \cdot{ }^{0} \mathrm{C}}$
Off-gas velocity, $\mathrm{m} / \mathrm{s}$

Material thickness, m 
$\bullet$

- 


\subsection{REFERENCES}

Benzing, R. J., and J. E. Myers. 1955. "Low Frequency Bubble Formation at Horizontal Circular Orifices." Ind. Eng. Chem. 47:2087.

Callahan, F. J. 1985. Swagelok Tube Fitting and Installation Manual. Marked Service Co., Solon, Ohio.

Calvert, S. 1977. "How to Choose a Particulate Scrubber." Chemical Engineering (84) 18:54.

Calvert, S., and H. M. Englund. 1984. Handbook of Air Pollution Technology. John Wiley and Sons, New York.

Calvert, S., and S. Gandhi. 1977. Fine Particle Collection by a FluxForce/Condensation Scrubber: Pilot Demonstration. EPA-600/2-77-238, U.S. Environmental Protection Agency, Washington, D.C.

Calvert, S., S Gandhi, D. L. Harmon and L. E. Sparks. 1977. "FF/C Scrubber Demonstration on a Secondary Metals Recovery Furnace." J. Air Pollut. Control Assoc. 27(11): 1076.

Calvert, S., and N. C. Jhaveri. 1974. "Flux Force/Condensation Scrubbing." J. Air Pollut. Control Assoc. 24(10):946.

Davies, C. N. 1973. Air Filtration, p. 50. Academic Press, New York.

Garner, F. H., and D. Hammerton. 1954. "Circulation Inside Gas Bubbles." Chem. Eng. Sci. 3(1):1.

Goldshmid, Y., and S. Calvert. 1963. "Small Particle Collection by Supported Liquid Drops." AIChE J. 9:352.

Gurley, R. N., K. M. LaRue, R. J. Thompson, J. R. Shah, J. E. Minor and D. H. Siemens. 1986. "Design Aspects of the Hanford Waste Vitrification Plant." In Proceedings of the Symposium on Waste Management. Tucson, Arizona.

Hesketh, H. E. 1986. Five Particles in Gaseous Media. Lewis Publishers, Inc., Chelsea, Michigan.

Hidy, G. M. 1984. Aerosols - An Industrial and Environmental Science. Academic Press, Inc., New York.

Hilliard, R. K., J. D. McCormack and A. K. Postma. 1981. Submerged Gravel Scrubber Demonstration as a Passive Air Cleaner for Containment Venting and Purging with Sodium Aerosols. HEDL-TME 81-30, Hanford Engineering Development Laboratory, Richland, Washington. 
Hinds, W. C. 1982. Aerosol Technology: Properties, Behavior, and Measurement of Airborne Particles. John Wiley and Sons, New York.

Holman, J.P. 1981. Heat Transfer. McGraw-Hill, New York.

Jacko, R. B., and M. L. Holcomb. 1978. "Parametric Study of Flux Force/ Condensation Scrubber for the Removal of Fine Hydrophobic Particles." In Proceedings of the Air Pollution Control Association, Vol. 2, June 25-30, Houston, Texas.

Kitamura, M., M. Hatta, R. Tatsugue, T. Takeda, M. Hagiwara, N. Sasaki, H. Kashihara and M. Yamamoto. 1986. "Development of HLLW Vitrification OffGas Treatment Process in Japan." In Proceedings of Spectrum 86 Conference, September 14, 1986, American Nuclear Society, Niagra Falls, New York.

Levich, V. G. 1962. Physiochemical Hydrodynamics. Prentice-Hall, Inc., New Jersey.

McCarthy, D., A. J. Yankel, R. G. Patterson and M. L. Jackson. 1976. "MultiStage Fluidized Bed Collection of Aerosols." Ind. Eng. Chem. Process Des. Dev. $15(2): 266$.

Miyahara, T., M. Hamaguichi, Y. Sukeda and T. Takahashi. 1986. "Size of Bubbles and Liquid Circulation in a Bubble Column with a Draught Tube and Sieve Plate." Can. J. Chem. Eng. 64(5):718.

Perry, R. H. and D. W. Green. 1984. Perry's Chemical Engineers' Handbook, 6th Ed. McGraw Hill, New York.

Postma, A. K. "Method for Removing Particulate Matter From a Gas Stream," U.S. Patent 4,432,777, 1984.

Randa11, C. T. and D. M. Sabatino. 1986. "Off-Gas System for the Savannah River Plant Defense Waste Processing Facility." Presented at American Nuclear Society Spectrum '86 International Meeting, September 14-18, 1986, Niagara Falls, New York.

Reid, R. C., J. M. Prausnitz and T. K. Sherwood. 1977. Properties of Gases and Liquids. McGraw-Hill, New York.

Rich, S. R., and T. G. Pantazelos. 1974. "Flux Force Condensation Aspirative Wet Scrubbing of Submicron Particles." J. Air Pollut. Control Assoc. 24(10): 952 .

Ruecker, C. M., and P. A. Scott. 1986. Parameters Influencing the Scrubbing Performance of the Submerged-Bed Scrubber. PNL-6035, Pacific Northwest Laboratory, Richland, Washington.

Schifftner, K. C., and H. E. Hesketh. 1986. Wet Scrubbers. Lewis Publishers, Inc., Chelsea, Michigan. 
Scott, P. A., R. W. Goles and R. D. Peters. 1985. Technology of Off-Gas Treatment for Liquid-Fed Ceramic Melters. PNL-5446, Pacific Northwest Laboratory, Richland, Washington.

Shaw, D. T. 1978. Recent Developments in Aerosol Science. John Wiley and Sons, New York.

Smith, J. M., and H. C. Van Ness. 1975. Introduction to Chemical Engineering Thermodynamics. McGraw-Hi11, New York.

Wu, F. H. 1984. "Drum Separator Design, A New Approach." Chemical Engineering $91(7) 74(4 / 2 / 84)$. 
$+$ , 
APPENDIX

DESIGN OF THE PACKING SUPPORT/GAS DISTRIBUTION PLATE 
APPENDIX

\section{DESIGN OF THE PACKING SUPPORT/GAS DISTRIBUTION PLATE}

Aerosols in the off gas, which bubble through the SBS, must diffuse from the bulk of the gas to the gas-liquid interface where they can be absorbed by the scrubbing liquor. The capture rate will therefore be a function of the distance aerosols must travel before coming in contact with the scrubbing solution. If the off gas can be distributed as very small bubbles, the aerosol transport distances will be shorter, and the probability of an aerosol contacting the scrubbing solution will be greatly increased.

A gas distributor capable of producing small bubbles can be incorporated into the design of the packing support plate. Sieve plates are generally used for this purpose. From a gas distribution point of view, the critical design parameters of a sieve plate include the spacing of the orifices and the diameter of the orifices (Klug and Vogelpohl 1986). Usually the hole spacing is about three times that of the hole diameter (Valentin 1967). Down to a certain size, the bubble diameter will decrease with a decrease in the orifice size. However, small orifices will be more susceptible to plugging with solids, and the minimum size should be at least three times larger than the largest particle expected.

A standard equation for flow through an orifice can be used to relate the overall pressure drop of the sieve plate to the hole diameter and the total gas flow rate (Crane Company 1976).

$$
\frac{F}{A n}=5.15 \frac{{Y d_{0}{ }^{2} \mathrm{C}}_{S_{g}}}{\Delta P p}
$$

where $F=$ gas flow rate at 1 atm and $15.6^{\circ}, \mathrm{m}^{3} / \mathrm{hr}$

$A=$ cross-sectional area of the bed, $m^{2}$

$n=$ area concentration of holes, $m^{-2}$ 


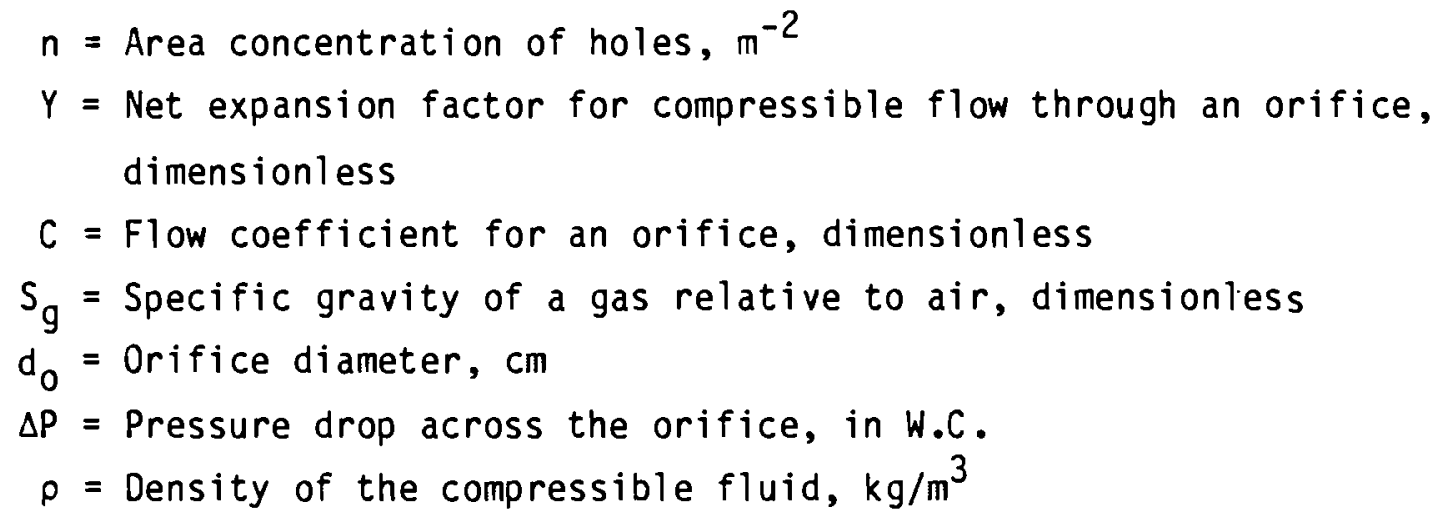

For typical SBS applications, equation A.l reduces to

$$
\frac{F}{A n}=3.09 d_{0}^{2} \sqrt{\Delta P \rho}
$$

Equation $A .2$ can then be used to determine the spacing of the holes in the sieve tray by specifying the desired pressure drop across the distribution plate and the size of the holes. Typically, a pressure drop of 2 to 4 inches of water column should be incurred across the distribution plate to ensure that the off gas below the plate will expand to the periphery of the plate.

The size of the bubble produced by the orifice will be a function of the size of the hole, the flow rate through the hole, and the physical properties of the surrounding liquid (Miyahara et al. 1986; Benzing and Myers 1955; Eversole, Wagner and Stackhouse 1941; Pattle 1950; van Krevelen and Hoftijzer 1950; Hayes, Hardy and Holland 1959; Sullivan, Hardy and Holland 1964; Satyanarayan, Kumar and Kuloor 1969; and Khurana and Kumar 1969).

At very low flow rates, the resulting bubble diameter can be calculated from a Force balance relating the buoyancy of the bubble to the surface tension holding it to the orifice (Valentin 1967). The resulting equation is shown below:

$$
d_{b}=\left[6 d_{0} \sigma /\left(\rho_{L}-\rho_{g}\right) g\right]^{1 / 3}
$$


where $d_{b}=$ bubble diameter, $c m$

$d_{0}=$ orifice diameter, $\mathrm{cm}$

$\sigma=$ surface tension of the liquid, dyne $/ \mathrm{cm}$

$\rho_{L}=$ liquid density, $\mathrm{g} / \mathrm{cm}^{3}$

$\rho_{\mathrm{g}}=$ gas density, $\mathrm{g} / \mathrm{cm}^{3}$

$g=$ gravitational constant, $\mathrm{cm} / \mathrm{sec}^{2}$

For air and water systems at $20^{\circ} \mathrm{C}$, Equation (A.3) reduces to

$$
d_{b}=\left(0.44 d_{0}\right)^{1 / 3}
$$

The approximate correctness of Equation (A.4) was verified by the data of Datta, Napier and Newitt (1950) for orifices ranging in diameter from 0.022 to $0.519 \mathrm{~cm}$. This range will include most applications of the SBS.

Equations (A.3) and (A.4) are true for low gas velocities. As the flow rate increases, the bubble diameter at first remains reasonably constant while the frequency of bubble formation increases. At higher flow rates, the frequency of formation remains essentially constant while the bubble diameter increases.

Equations (A.3) and (A.4) will hold up to an orifice Reynolds number of approximately 200. In this range, the bubble diameter remains constant and the frequency of formation increases. Above an orifice Reynolds number of 200, the bubbles will slowly increase in size as the gas flow rate is increased.

Once the orifice Reynolds number reaches approximately 1,000 , bubbles will form at the orifice at a constant frequency, and the bubble diameter will vary depending on the flow rate of the gas. Large-diameter orifices will result in a frequency of 15 bubbles per second, while small orifices will have a bubble formation frequency of about 45 bubbles per second. At an orifice number of about 2,000 , the bubbles begin to break up from turbulence.

The discussion presented here has focused on bubble formation at a submerged orifice; influence of packing material, as would be present in the SBS, 
has not been considered. Consequently, this information can only be used as an approximation of the bubble size.

It was suggested previously that the bubble size should be minimized to reduce the transport distances from the bulk of the gas within the bubble-toliquid interface. However, it may not be desirable to reduce the bubble size below a certain volume. It has been shown by Garner and Hammerton (1954) that the gas inside bubbles will circulate due to the viscous drag of the outer fluid. A current will develop, flowing up the central axis and down the sides of the bubble.

Bubbles below $0.015 \mathrm{~cm}$ in diameter will rise in water as rigid spheres; therefore, it may not be desirable to form bubbles smaller than $0.015 \mathrm{~cm}$ because any gain in the collection efficiency of the aerosols as a result of shorter transport distances may not compensate for the loss of circulation within the bubble. If bubbles much smaller than $0.015 \mathrm{~cm}$ can be formed, the lack of circulation may no longer be significant in comparison to the much smaller transport distances and the fact that the residence time of the bubble will be much longer due to the lower terminal velocities for small bubbles (Garner and Hammerton 1954).

A good hole diameter for the SBS is about $0.16 \mathrm{~cm}$. The bubbles resulting from an orifice of this diameter should be somewhat larger than $0.4 \mathrm{~cm}$. Bubbles in this range will exhibit gas circulation within the bubble and rise at a terminal velocity of approximately $25 \mathrm{~cm} / \mathrm{sec}$.

\section{REFERENCES}

Benzing, R. J., and J. E. Myers. 1955. "Low Frequency Bubble Formation at Horizontal Circular Orifices." Ind. Eng. Chem. 47:2087.

Crane Company. 1976. Flow of Fluids Through Valves, Fittings, and Pipe. Technical Paper No. 410.

Datta, R. L., D. H. Napier and D. M. Newitt. 1950. "The Properties and Behavior of Gas Bubbles Formed at a Circular Orifice." Trans. Inst. Chem. Engrs. 28:14.

Eversole, W. G., G. H. Wagner and E. Stackhouse. 1941. "Rapid Formation of Gas Bubbles in Liquids." Ind. Eng. Chem. 33(11):1459. 
Garner, F. H., and D. Hammerton. 1954. "Circulation Inside Gas Bubbles." Chem. Eng. Sci. 3(1):1.

Hayes, W. B., B. W. Hardy and C. D. Holland. 1959. "Formation of Gas Bubbles at Submerged Orifices." AIChE J. 5(3):319.

Khurana, A. K. and R. Kumar. 1969. "Studies in Bubble Formation-III." Chem. Eng. Sci. 24:1711.

Klug, P., and A. Vogelpohl. 1986. "Bubble Formation at Sieve Plates - Effects on Gas Hold-Up in Bubble Columns." Ger. Chem. Eng. 9:93.

Miyahara, T., M. Hamaguichi, Y. Sukeda and T. Takahashi. 1986. "Size of Bubbles and Liquid Circulation in a Bubble Column with a Draught Tube and Sieve Plate." Can. J. Chem. Eng. 64(5):718.

Pattle, R. E. 1950. "Part II Factors in the Production of Small Bubbles." Trans. Inst. Chem. Engrs. 28:32.

Satyanarayan, A. R. Kumar and N. R. Kuloor. 1969. "Studies on Bubble Formation-II Bubble Formation Under Constant Pressure Conditions." Chem. Eng. Sci. 24:749.

Sullivan, S. L., B. W. Hardy and C. D. Holland. 1964. "Formation of Air Bubbles at Orifices Submerged Beneath Liquids." AIChE J. 10(6):848.

Valentin, F. H. H. 1967. Absorption in Gas-Liquid Dispersions: Some Aspects of Bubble Technology, p. 6,105. E. \& F. N. Spon Ltd., London.

van Krevelen, D. W., and P. J. Hoftijzer. 1950. "Studies of Gas-Bubble Formation." Chem. Eng. Prog. 46(1):29. 


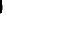




\section{DISTRIBUTION}

No. of

Copies

OFFSITE

30 DOE Technical Information Center

6 DOE Office of Civilian

Radioactive Waste Management Forrestal Building

Washington, DC 20585

ATTN: C. R. Cooley, RW-4

J. R. Hilley, RW-30

S. Kale, RW-20

D. E. Shelor

R. Stein, RW-23

L. H. Barrett, RW-33

3 DOE Office of Defense Waste \& GTN

Transportation Management

Washington, DC 20545

ATTN: G. H. Daly, DP -124

J. E. Lytle, $D P-12$

T. C. Chee, DP -123

4 DOE Office of Remedial Action and Waste Technology GTN Washington, DC 20545

ATTN: J. A. Coleman, NE-24

T. W. McIntosh, NE-24

W. R. Voigt, NE-20

H. F. Walter, NE-24

A. T. Clark

Division of Fuel Material Safety

Nuclear Regulatory Commission Washington, DC 20555
No. of

Copies

V. Stello

Office of the Executive

Director for Operations

Mail Station 6209

Nuclear Regulatory Commission

Washington, DC 20555

G. L. Sjoblom

Environmental Protection Agency

Office of Radiation Programs

401 M Street, S.W.

Washington, DC 20460

J. M. McGough

DOE Albuquerque Operations Office

P.0. Box 5400

Albuquerque, NM 87185

P. G. Hagan

Joint Integration office

Bldg. 3, 2nd Floor

2201 San Pedro N.E.

Albuquerque, NM 87110

E. Maestas

DOE West Valley Operations Office

P.0. Box 191

West Valley, NY 14171

2 DOE Idaho Operations Office

550 Second Street

Idaho Falls, ID 83401

ATTN: S. T. Hinschberger

J. P. Hamric

F. T. Fong

DOE San Francisco Operations

1333 Broadway

Oakland, CA 94612 
M. R. Jugan

DOE Oak Ridge Operations Office

P.0. Box E

Oak Ridge, TN 37830

W. J. Brumley

DOE Savannah River Operations Office

P.0. Box A

Aiken, SC 29801

M. J. Steindler

Argonne National Laboratory

9700 South Cass Avenue

Argonne, IL 60439

C. S. Abrams

Argonne National Laboratory

P.0. Box 2528

Idaho Falls, ID 83401

3 Battelle Memorial Institute

Project Management Division 505 King Avenue

Columbus, $\mathrm{OH} 43201$

ATTN: W. A. Carbeiner

W. S. Madia

Technical Library

L. D. Ramspott

Lawrence Livermore National Laboratory

University of California

P.0. Box 808

Livermore, CA 94550

D. T. Oakley, MS 671

Los Alamos Scientific Laboratory

P.0. Box 1663

Los Alamos, NM 87544
4 Oak Ridge National Laboratory P.0. Box $Y$

Oak Ridge, TN 37830

ATTN: J. 0. Blomeke

W. D. Burch

R. T. Jubin

L. J. Mezga

Sandia Laboratories

P.0. Box 5800

Albuquerque, NM 87185

ATTN: Technical Library

J. R. Berreth

Westinghouse Idaho Nuclear Co., Inc.

P.0. Box 4000

Idaho Falls, ID 83401

6 E. I. du Pont de Nemours Company

Savannah River Laboratory

Aiken, SC 29801

ATTN: M. D. Boersma

J. G. Glasscock

R. G. Baxter

J. R. Knight

M. J. Plodinec

C. T. Randall

E. A. Jennrich

EG\&G Idaho

P.0. Box 1625

Idaho Falls, ID 83415

R. Shaw

Electric Power Research

Institute

3412 Hillview Avenue

P.0. Box 10412

Palo Alto, CA 94304 
No. of

Copies

5 West Valley Nuclear Services Company

P.0. Box 191

West Valley, NY 14171

ATTN: S. M. Barnes

C. C. Chapman

J. E. Krauss

S. J. Marchette

J. M. Pope

J. L. White

Energy Research \& Development Authority

Empire State Plaza

Albany, NY 12223

A. K. Postma

Rt. 1, Box 46A

Halfway, OR 97834

ONSITE

9 DOE Richland Operations Office

J. H. Anttonen

E. A. Bracken

G. J. Bracken

C. E. Collantes

C. R. DeLannoy

H. M. Peterson

J. L. Rhoades

M. W. Shupe

J. D. White

9 Rockwell Hanford Operations

T. D. Anderson

J. M. Henderson

R. D. Prosser

J. L. Scott

D. A. Turner

D. D. Wodrich

R. D. Wojtasek

B. D. Wolfe

File Copy
No. of

Copies

UNC United Nuclear Industries

T. E. Dabrowski/W. J. Kyriazia

2 Westinghouse Hanford Company

R. E. Lerch

J. D. Watrous

51 Pacific Northwest Laboratory

C. R. Allen

W. W. Ballard, Jr.

W. F. Bonner

R. A. Brouns

J. L. Buelt

H. C. Burkholder

J. R. Carrell

R. D. Dierks

L. J. Ethridge

R. W. Goles

L. K. Holton

S. S. Koegler

W. L. Kuhn

L. T. Lakey (2)

D. E. Larson

J. L. McElroy

A. H. McMakin

J. E. Minor

R. K. Nakaoka

J. M. Perez, Jr.

R. D. Peters

M. E. Peterson

C. M. Ruecker (10)

P. A. Scott (5)

G. J. Sevigny

S. C. Slate

J. E. Surma

N. M. Thomas

J. H. Westsik, Jr.

Publishing Coordination (2)

Technical Report Files (5) 
